$$
\text { DOE/mc/31176--DT }
$$

DE-FC21-95MC31176-07

\title{
Utility Advanced Turbine Systems (ATS) Technology Readiness Testing and Pre-Commercial Demonstration
}

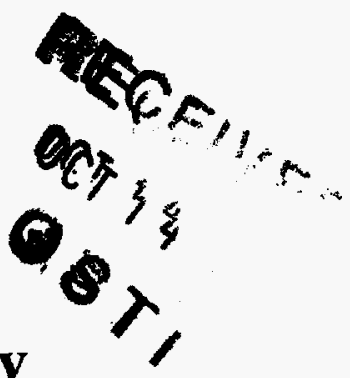

\author{
Quarterly Report \\ January 1 - March 31, 1997
}

Work Performed Under Contract No.: DE-FC21-95MC31176

For

U.S. Department of Energy

Office of Fossil Energy

Federal Energy Technology Center

P.O. Box 880

Morgantown, West Virginia 26507-0880

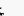

By

General Electric Company

Power Generation Engineering

Schenectady, New York 12345 


\section{Disclaim er}

This report was prepared as an account of work sponsored by an agency of the United States Government. Neither the United States Government nor any agency thereof, nor any of their employees, makes any warranty, express or implied, or assumes any legal liability or responsibility for the accuracy, completeness, or usefulness of any information, apparatus, product, or process disclosed, or represents that its use would not infringe privately owned rights. Reference herein to any specific commercial product, process, or service by trade name, trademark, manufacturer, or otherwise does not necessarily constitute or imply its endorsement, recommendation, or favoring by the United States Government or any agency thereof. The views and opinions of authors expressed herein do not necessarily state or reflect those of the United States Government or any agency thereof. 


\section{DISCLAIMER}

Portions of this document may be illegible in electronic image products. Images are produced from the best available original document. 
Section 1 Executive Summary

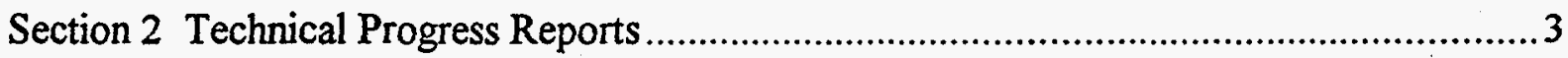

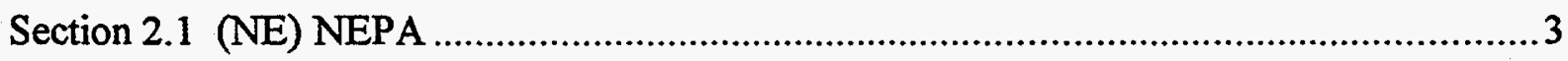

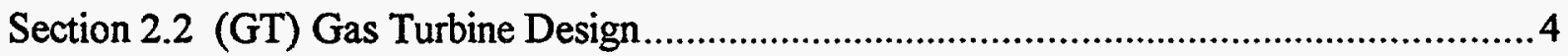

Section 2.2.1 (GTAD) Aerodynamic Design .....................................................................

Section 2.2.2 (GTFF) Gas Turbine Flange-to-Flange Design............................................ 4

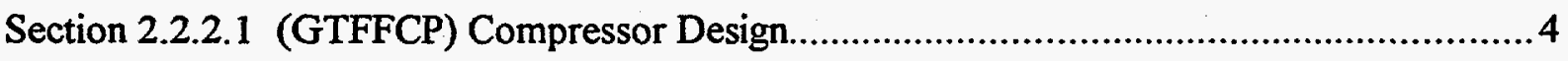

Section 2.2.2.2 (GTFFCB) Combustor Design............................................................. 5

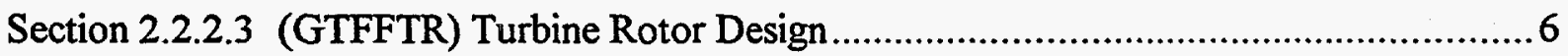

Section 2.2.2.3.1 (GTFFTR) Turbine Rotor Mechanical Analysis (Task Force).................... 7

Section 2.2.2.3.2 (GTFFTR) Wheel Forging Residual Stress Analysis................................ 8

Section 2.2.2.3.3 (GTFFTR) Rotor Steam Circuit Analysis...........................................

Section 2.2.2.3.4 (GTFFTR) Turbine Rotor Shaft Temperature Analysis - \#2 Bearing ........ 10

Section 2.2.2.3.5 (GTFFTB) Bucket Temperature Monitoring ........................................ 11

Section 2.2.2.4 (GTFFTB) Turbine Bucket Design .................................................... 11

Section 2.2.2.4.1 (GTFFTB) Wheel Dovetail Analysis - S1B and S2B ........................... 12

Section 2.2.2.4.2 (GTFFTB) 9H Tip Shroud Design Optimization - S3B and S4B ............ 13

Section 2.2.2.4.3 (GTFFTB) Bucket Wide Grain Sensitivity Analysis .............................. 13

Section 2.2.2.4.3.1 (GTFFTB) 9H Robust Design and Life Assessment - S1B ................... 14

Section 2.2.2.4.4 (GTETIH) Bucket Tip Treatment Heat Transfer................................... 14

Section 2.2.2.4.5 (GTFFTB) Air/Steam Coolant Transition Analysis - S1B and S2B.......... 15

Section 2.2.2.4.6 (GTETEH) External Heat Transfer - S1B .............................................. 16

Section 2.2.2.5 (GTFFTS) Turbine Stator Design......................................................... 17

Section 2.2.2.5.1 (GTFFTS) Turbine Stator Robust Design ........................................... 18

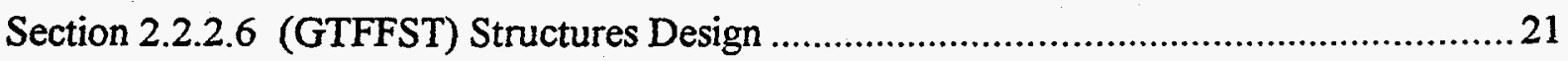

Section 2.2.2.6.1 (GTFFSTEF) Exhaust Diffuser Performance .........................................23

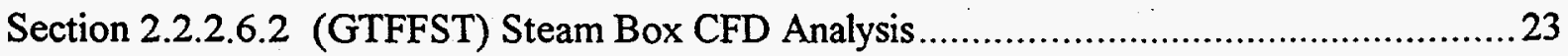

Section 2.2.2.7 (GTFFMS) Mechanical System Design..................................................2 24

Section 2.2.2.7.1 (GTFFMS) Transient Gas Turbine Cycle Platform Evaluation..................25

Section 2.2.2.8 (GTFFPP) On-Base and External Piping Design .....................................26

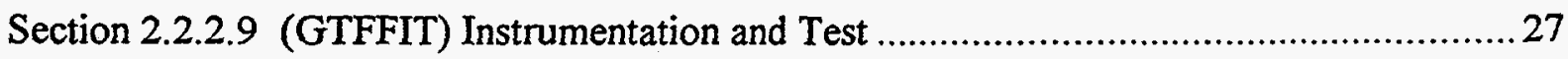

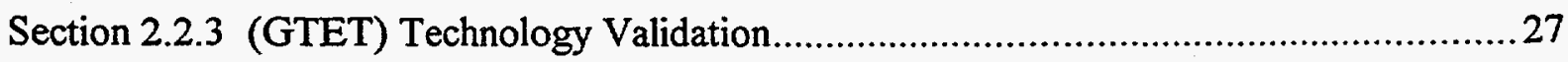


Section 2.2.3.1 (GTETNC) S1N Design

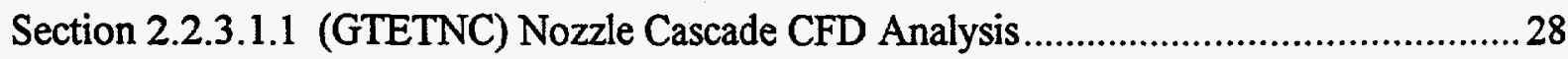

Section 2.2.3.1.2 (GTETEH) Combustion-Generated Flow Effects on Heat Transfer...........28

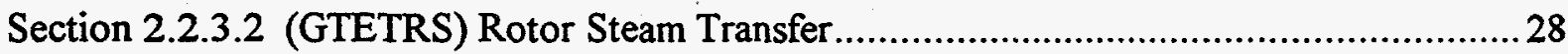

Section 2.2.3.3 (GTETSE) Rotor-Bucket Steam Transfer Spoolie .....................................29

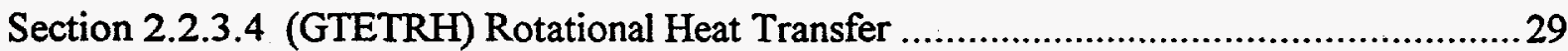

Section 2.2.3.4.1 (GTETRH) Rotational Effects on Bucket Mixing Ribs...........................29

Section 2.2.3.4.2 (GTETRH) Bucket Cooling Circuit Rotational Pressure Drop Test .......... 30

Section 2.2.3.5 (GTETIH) Surface Enhanced Internal Heat Transfer ................................... 31

Section 2.2.3.5.1 (GTETS2NHT) Trailing Edge Flow Test - S2N .................................... 31

Section 2.2.3.5.2 (GTETIH) Trailing Edge Heat Transfer Tests - S2B .............................. 31

Section 2.2.3.5.3 (GTETIH) Outer Band Liquid Crystal Heat Transfer Tests - S1N.............32

Section 2.2.3.5.4 (GTETIH) Convex Cavity Heat Transfer Tests - SIN.............................. 33

Section 2.2.3.5.5 (GTETIH) Bucket Tip Closed Circuit Cooling ........................................ 33

Section 2.2.3.5.6 (GTETLE) Bucket Leading Edge Heat Transfer Testing .........................34

Section 2.2.3.5.7 (GTETIH) Surface Enhanced Internal Heat Transfer - SIN ....................34

Section 2.2.3.5.8 (GTETIH) Trailing Edge Heat Transfer Tests - S1N .............................35

Section 2.2.3.5.9 (GTETBKHT) High Reynolds Number Turbulator Static Heat

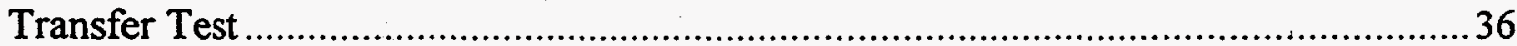

Section 2.2.3.5.10 (GTET) Impingement Degradation Effects .........................................36

Section 2.2.3.5.11 (GTETH) Production Airfoil Flow Checks .........................................37

Section 2.2.3.6 (GTETEH) Surface Roughness Effects on Heat Transfer.............................38

Section 2.2.3.6.1 (GTETEH) Heat Transfer for Production Aero with TBC Spall Effects -

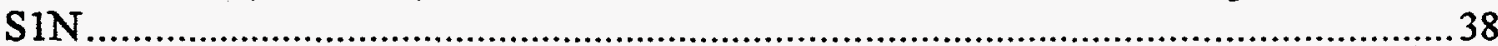

Section 2.2.3.6.2 (GTETEH) Surface Roughness Effects on Heat Transfer.........................39

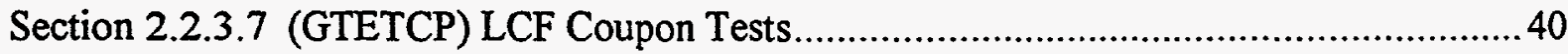

Section 2.2.3.7.1 (GTETCP) LCF and Crack Propagation Rate Tests................................40

Section 2.2.3.8 (GTETSP) Steam Particulate Deposition ................................................... 41

Section 2.2.3.8.1 (GTETSP) Steam Particulate Deposition Rig Testing .............................. 41

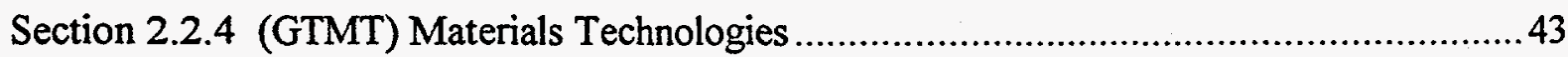

Section 2.2.4.1 (GTMTSE) Steam Effects on Mechanical Properties .................................43

Section 2.2.4.2 (GTMTSO) Oxidation Due to Steam...................................................... 43

Section 2.2.4.3 (GTMTCE) Corrosion Rate Evaluations of Airfoil Overlay Coatings ........... 44 
Section 2.2.4.4 (GTMTBV) Compressor Blades and Vanes Materials and Processes .45

Section 2.2.4.5 (GTMTVG) Compressor Variable Guide Vane System Design Support and Process Development

Section 2.2.4.6 (GTMTCS) Compressor Structural Materials and Processes. .45

Section 2.2.4.7 (GTMTRF) Turbine Rotor Forging Materials and Processes. .46

Section 2.2.4.8 (GTMTRS) Turbine Rotor Spoolies and Transfer Devices Materials and Processes .47

Section 2.2.4.9 (GTMTSB) Structural Bolting ............................................................ 48

Section 2.2.4.10 (GTMTTA) Turbine Airfoils Materials and Processes.............................. 48

Section 2.2.4.11 (GTMTCB) Combustion Materials and Processes.................................... 49

Section 2.2.4.12 (GTMTST) Turbine Structures Materials and Processes ............................50

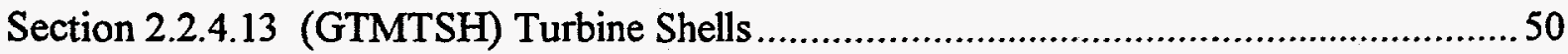

Section 2.2.4.14 (GTMTSR) Seal Technology ............................................................ 51

Section 2.2.4.14.1 (GTFFTSSESV) Hot Gas Path and Transition Piece Cloth Seals ...........51

Section 2.2.4.14.2 (GTETBS) Steam Gland Brush Seals...............................................52

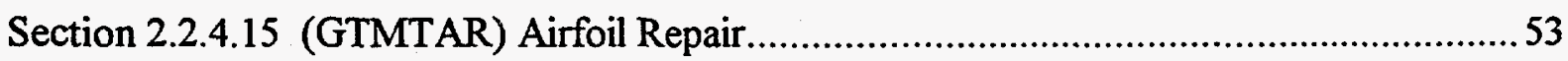

Section 2.2.5 (GTTT) Thermal Barrier Coating Technology ............................................5

Section 2.2.5.1 (GTTTSD) Coating System Development …………..............................5

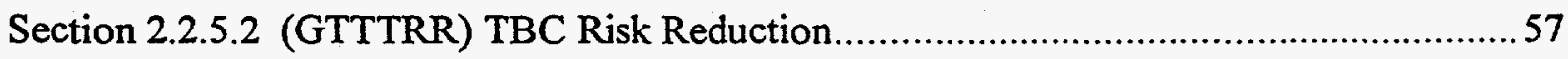

Section 2.2.5.3 (GTTTDD) TBC Design Data and Life Analyses....................................58

Section 2.2.5.3.1 (GTFFTB) Bucket TBC Roughness and Spall Characterization ................60

Section 2.3 (CC) Combined Cycle Integration ...............................................................61

Section 2.3.1 (CCSD) Combined Cycle Systems Design ....................................................61

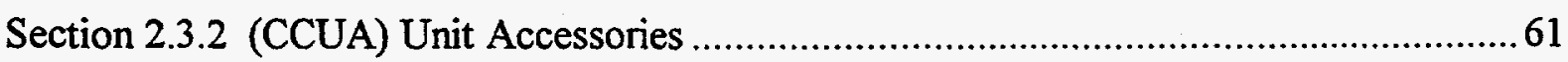

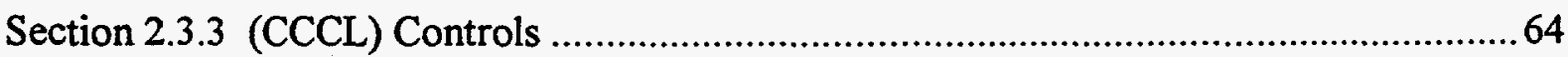

Section 2.3.4 (CCRA) Reliability, Availability, and Maintainability (RAM) Analysis.............65

Section 2.4 (MF) Manufacturing Equipment and Tooling..................................................66

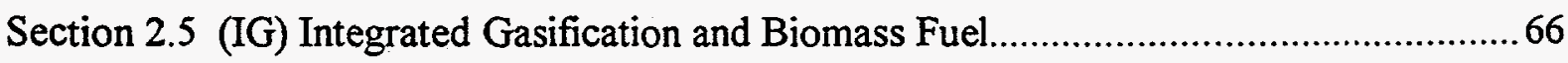

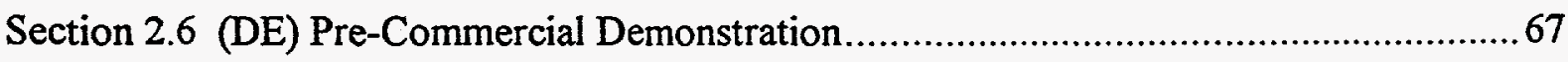

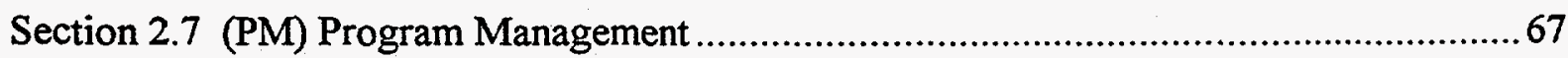

\section{LIST OF FIGURES}

Figure 1-1. Schematic of $\mathrm{H}$ machine cross section 


\section{Section 1 Executive Summary}

The overall objective of the Advanced Turbine System (ATS) Phase 3 Cooperative Agreement between GE and the U.S. Department of Energy (DOE) is the development of the GE $7 \mathrm{H}$ and $9 \mathrm{H}$ combined cycle power systems. The major effort will be expended on detail design. Validation of critical components and technologies will be performed including: hot gas path component testing, sub-scale compressor testing, steam purity test trials, and rotational heat transfer confirmation testing. Processes will be developed to support the manufacture of the first system, which will be sited and operated in Phase 4. Technology enhancements that are not required for the first machine design but will be critical for future ATS advances in performance, reliability, and costs will be initiated. Long-term tests of materials to confirm design life predictions will continue. A schematic of the GE $\mathrm{H}$ machine is shown in Figure 1-1.

This report summarizes work accomplished in 1Q97. The most significant accomplishments are listed below:

\section{H/7H-common technology}

- Initial gas turbine transient cycle model completed

- Tooling for all 9H turbine buckets completed; fourth-stage casting trials completed

- Telemetry system selected for transmitting instrumentation data from rotating components

- Control algorithms for startup and shutdown developed; conceptual design of Integrated Control System completed

- TBC Rainbow test completed; extended time effects on various TBC systems evaluated under engine conditions

- $9 \mathrm{H}$ compressor rig assembly completed; preparation for $2 \mathrm{Q} 97$ test continues

- Combustion test hardware procurement completed

- Casting trials initiated on 9H first-, second-, and third-stage buckets; production initiated on $9 \mathrm{H}$ third-stage bucket

- FMEAs completed on exhaust frame, combustor end cover, steam gland, third-stage bucket cooling delivery, and compressor rotor cooling system

- Program review held with GE Corporate Review Board

- Development/conceptual review completed for an integrated pressure recovery duct with optimized performance

\section{H-related}

- $7 \mathrm{H}$ compressor blade designs completed for stages 4 through 17 


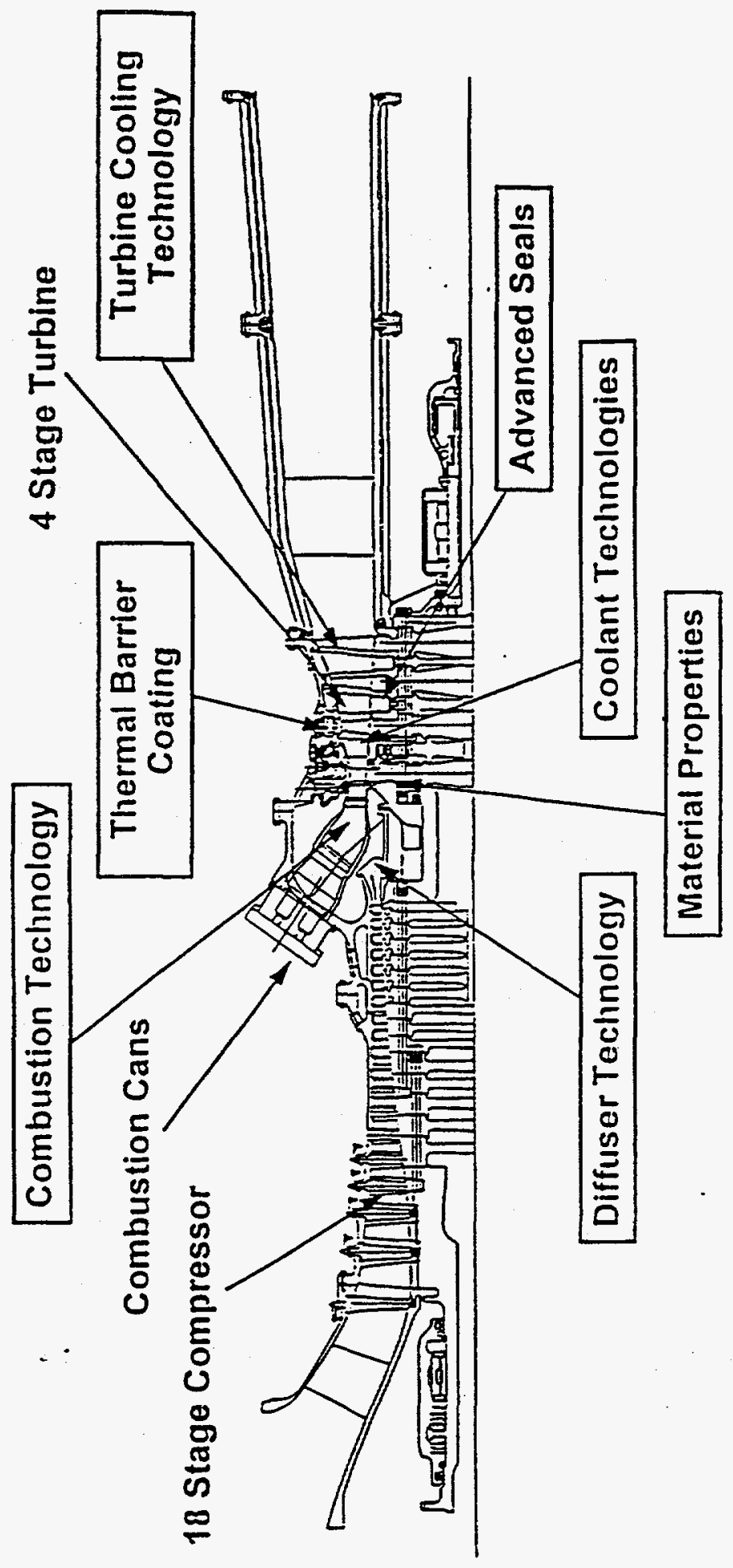

Figure 1-1. Schematic of $\mathrm{H}$ machine cross section 


\section{Section 2 Technical Progress Reports}

\section{Section 2.1 (NE) NEPA}

\section{Objective}

A draft topical report will be prepared which provides the environmental information associated with Phase 3, Technology Readiness Testing, as specified in the National Environmental Policy Act (NEPA). DOE will use this information to prepare the NEPA documentation for Phase 3. DOE will review the report and advise the participant of the acceptability of the report or the need for additional information. A final report will then be submitted.

A second draft topical report will be prepared which provides the environmental information associated with Phase 4, Pre-Commercial Demonstration, as specified in NEPA. DOE will use this information to prepare the NEPA documentation for Phase 4. DOE will review the report and advise the participant of the acceptability of the report or the need for additional information. A final report will then be submitted.

\section{Progress}

The Phase 3 topical NEPA report was completed. An outside consulting firm, ERM, Inc., specializing in the area of environmental compliance, was contracted to support informationgathering, assessment, and report preparation. Information was gathered on planned program test activities at the Schenectady main plant and the GE Corporate Research and Development (CRD) facility in Schenectady, NY, and the GE Aircraft Engines (GEAE) test facilities in Evendale, $\mathrm{OH}$, and Lynn, MA. The NEPA topical report was prepared, reviewed, and submitted. All sites were found to have the necessary permits to support the Phase 3 activities either in place or in the process of being obtained.

At DOE's request a supplemental table was submitted for the ATS Phase 3 NEPA Topical Report. This table summarizes process feedstocks used and environmental releases from ATS Phase 3 Program test activities for all sites. Quantitative information necessary for DOE to issue the Phase 3 NEPA Comprehensive Exclusion was provided.

The Phase 4 topical NEPA report was also completed. This report took the form of a "generic" Environmental Information Volume (EIV). ERM, Inc., was again contracted to provide support. The GE Power Systems' engineering power plant projects environmental organization, working with ERM, prepared the report. The technical basis for the report was the $7 \mathrm{H}$ Base Reference Plant. After review by DOE, the report was resubmitted after proprietary data were removed. 


\section{Section 2.2 (GT) Gas Turbine Design}

\section{Section 2.2.1 (GTAD) Aerodynamic Design}

\section{Objective}

To achieve ATS performance goals, a four-stage turbine will be designed. Advanced aerodynamic technology (sometimes called 3D aerodynamics) pioneered at GE Aircraft Engines (GEAE) will be applied to each stage to maximize performance and meet mechanical design requirements required by steam cooling technology.

The $7 \mathrm{H}(60 \mathrm{~Hz})$ and $9 \mathrm{H}$ turbines $(50 \mathrm{~Hz})$ have similar flow paths and a common rotor, but require different aerodynamic designs. Performance requirements for the $7 \mathrm{H}$ and $9 \mathrm{H}$ turbine aerodynamics are the same.

\section{Progress for this Quarter}

The final $7 \mathrm{H}$ turbine aerodynamic flow path was completed, formally reviewed, and documented. All mechanical issues related to flow path aerodynamics were resolved.

\section{Plans for Next Quarter}

No activity is planned for this task in $2 \mathrm{Q} 97$.

\section{Technology Application}

Advanced aerodynamic technology (sometimes called 3D aerodynamics) pioneered at GEAE has been applied to each stage to maximize performance and meet mechanical design objectives required by steam cooling technology.

\section{Section 2.2.2 (GTFF) Gas Turbine Flange-to-Flange Design}

\section{Section 2.2.2.1 (GTFFCP) Compressor Design}

\section{Objective}

The objective of this task is to design $7 \mathrm{H}$ and $9 \mathrm{H}$ compressor rotor and stator structures with the goal of achieving lower cost and greater durability by applying proven GE Power Generation heavy-duty use design practices. The designs will be based on the GEAE CF6-80C2 compressor. Transient and steady-state thermomechanical stress analysis will be run to ensure compliance with GEPG life standards. Drawings will be prepared for forgings, castings, machining, and instrumentation for full speed, no load tests of the first unit.

\section{Progress for this Quarter}

The design of the $9 \mathrm{H}$ compressor is complete and all components were released for manufacture. The $9 \mathrm{H}$ compressor is on schedule to support the $9 \mathrm{H}$ program test requirements. During 1Q97, instrumentation and assembly drawings were initiated and will be completed during the next few months. 
A final assessment of the clearances prior to machine assembly and test is being completed to achieve good performance and operability of the compressor. This work includes a complete dimensional tolerance stack-up, a transient hot-to-cold deflection study, and an evaluation of off-design conditions such as stall. Final axial and radial clearances will be specified on assembly drawings.

Final assembly of the $9 \mathrm{H}$ sub-scale compressor test rig is being completed. The test vehicle is fully assembled with only the external actuation system hardware yet to be installed. This rig will be shipped and installed in the test facility during 2 Q97.

The $7 \mathrm{H}$ compressor airfoil blade design and drawings for stages 4 through 14 are complete for the sub-scale rig. Work continues on stages 0 through 3 . Rotor configurations and trade-off studies are being completed. Of particular importance is the selection of rotor material in the aft end.

\section{Plans for Next Quarter}

A $9 H$ sub-scale rig test in the Lynn, MA, facility will be initiated. Preliminary validation of the $9 \mathrm{H}$ product aerodynamic and aeromechanical characteristics will be obtained.

$9 \mathrm{H}$ product instrumentation and assembly drawings will be completed. Support for component manufacture will be provided as needed.

$7 \mathrm{H}$ product and sub-scale rig definitions will be completed. The design will be completed and drawings released for sub-scale test of the remaining rotor airfoils (stages 0 through 3 ). The flow path definition for the $7 \mathrm{H}$ compressor will be completed.

\section{Technology Application}

The compressor design (aerodynamic and mechanical) and rig test results establish the basis for the $7 \mathrm{H}$ and $9 \mathrm{H}$ production hardware.

\section{Section 2.2.2.2 (GTFFCB) Combustor Design}

\section{Objective}

The objective of this task is to design a combustor based on the commercial DLN2 combustion system, with modifications made for improved use of available air, reduced cooling, and greater load turndown capability. This design will be similar for both the $7 \mathrm{H}$ and 9H machines. It will be configured to ensure the ability to use preheated fuel. Rig testing of full-scale and scaled components will be conducted at $7 \mathrm{H}$ and $9 \mathrm{H}$ cycle conditions. The final configuration will be validated in single-combustor, full-scale tests under full operating conditions.

The premixer-burner design will be optimized to use minimum pressure drop, achieve required fuel/air mixing, maintain stable flame, and resist flashback. The basic design will be developed and evaluated in full-scale single burner tests and then implemented in full-scale combustors. The ability to meet high cycle fatigue (HCF) life goals depends on understanding the effects and interrelationships of all combustion parameters. Existing dynamics models used in parallel with laboratory-scale and full-scale testing will be used to predict combustor dynamic behavior. 
Chamber arrangement, casings, cap and liner assemblies, flame detectors, and spark plugs will be designed and analyzed to ensure adequate cooling, mechanical life, and aerodynamic performance. Fuel nozzles will be designed for operation on gas alone or on gas with distillate as a backup fuel. The transition piece will be designed and integrated with the design of the machine mid-section, transition duct cooling, and mounting.

A full-scale, single-combustor test stand will be designed and fabricated to verify performance of the combustion system. Facility modifications will be made to support the test. These include installation of the test stand, installation of high-temperature stainless steel air piping, an additional air heater, control systems, upgrades to the combustion video system, and tooling.

\section{Progress for this Quarter}

The test stand hardware fabrication and procurement cycle was initiated for casings, liners, flowsleeves, fuel nozzles, and endcovers. Transition piece casting was completed. Aft frame machining for the test transition piece was completed. Casting tooling for the transition piece bodies was completed. The impingement sleeve for the test stand transition piece was completed. Aft seals were procured. Test stand transition body assembly is underway. The test stand pressure vessel and nozzle box were delivered.

\section{Plans for Next Quarter}

All test stand hardware will be procured and fabricated. Trial fit-ups prior to test stand commissioning will start. Designs will be released for casting and fabrication of two additional fuel nozzle designs. Preparations for test stand commissioning will progress almost to completion for first testing during $3 \mathrm{Q} 97$.

\section{Technology Application}

Design and development of the combustion system is required for the ATS gas turbine to meet the low emissions targets at the high cycle conditions of inlet temperature, pressure, air flow, and outlet temperature, all of which are greater than those of any of GE's developed products.

\section{Section 2.2.2.3 (GTFFTR) Turbine Rotor Design}

\section{Objective}

The objective of this task is the design of turbine rotor components (wheels, spacers, aft shaft, transition discs, coolant systems, and fastening devices). Transient and steady-state stress analyses will be used to calculate parts lives. Rotor and system vibratory characteristics will be evaluated. The coolant flow circuit for routing the cooling steam to and from buckets will be designed and performance calculated. Test results will be incorporated concurrently. Drawings and specifications will be developed in preparation for manufacturing. 


\section{Progress for this Quarter}

The preliminary turbine rotor structural system model (transient thermal/mechanical) was modified with various component updates. A secondary flow Design of Experiments study evaluating secondary flow details such as flows and swirls is near completion.

A 3D mechanical analysis of the 1-2 spacer, a 2D pie thermal mechanical analysis of the 2-3 spacer, and a 3D mechanical analysis of the aft shaft were completed. A 3D thermal mechanical analysis of the second-stage dovetail and a 3D mechanical analysis of the thirdstage dovetail are $90 \%$ complete. The critical dimension drawing was issued for manufacturing tooling procurement. Work began on component final machining drawing.

\section{Plans for Next Quarter}

The preliminary turbine rotor structural system model startup and shutdown analysis will be complete.

A 3D mechanical analysis of the transition disc and marriage flange area will be complete. The final system model will be underway. The 3D thermal mechanical analysis of the 1-2 spacer and the aft shaft will be underway. The 3D thermal mechanical analysis of the second-stage dovetail and the 3D mechanical analysis of the third-stage dovetail will be complete. The turbine wheel final machine drawings will be issued.

\section{Technology Application}

The turbine rotor analysis and design effort defined the basis for the $7 \mathrm{H}$ and $9 \mathrm{H}$ production hardware.

\section{Section 2.2.2.3.1 (GTFFTR) Turbine Rotor Mechanical Analysis (Task Force)}

\section{Objective}

The objective of this task is to provide thermal and mechanical design and analysis support for rotor components of the ATS gas turbine. Analyses are run to determine temperature, displacement, and stress distributions for various components of the ATS gas turbine rotor. Initial designs and concepts are analyzed, compared, and modified to meet design specifications with respect to stress levels, low cycle fatigue (LCF) life, yielded volume, residual displacement, rabbet closure, etc.

\section{Progress for this Quarter}

Thermal and structural analyses of the bore tube end cap were run. These analyses indicate that the end cap stresses in the current design are high. A number of modifications to the end cap were evaluated, including the base design with a radial undercut, an axial hole at the center, and a combination of the two. The design with an axial hole at the center showed the best performance with respect to stress reduction because the vanes are freer to grow as a result of thermal expansion, thus reducing thermal stresses. This design was selected as the final design for the present.

Nonlinear, 3D stress analyses were run for the steam delivery system first- and second-stage bucket spoolies. The methodology is similar to the one developed for the axial tube spoolies. 
A Design of Experiments approach was used to assess design variables with the model. The analyses determined the proper interference fit to be used and the acceptability of the design for drawing release to manufacturing. The current spoolie analysis methodology was applied to a wear test specimen that survived 20,000 cycles at high interference and load. The results are being used as design limits for the actual designs.

The 3D finite element analysis of the third-stage dovetail was improved by adding an airfoil model to accurately distribute loads to the dovetail. Stress levels changed less than 5\% compared to the previous analysis in which forces were applied to represent the airfoil.

Further 3D stress analysis of the steam feed manifold is being run, concentrating on investigating various ways of strengthening the walls to withstand the pressure loading while keeping the weight down. Analyses were also run to investigate the additional stress produced in the manifold caused by the centrifugal effect of the axial tube. More recent stress analyses of the feed manifold concentrated on the $T$-shape rather than the delta-shape design. The focus of the new investigation is on the effect of isolating the through tubes that feed steam to the first-stage buckets. Three-dimensional stress analysis is temporarily on hold, while the effect of various design configurations on steam flow is being investigated elsewhere.

Plane stress analyses of four cross sections of the transition disk were run. A review was conducted of the stress levels obtained in the transition piece based upon plane-stress; i.e., pie slices of various cross sections. The stress levels obtained from these analyses look good from both yielding and life perspectives. However, the initial design does not meet the contactsurface-area to bolt-hole-area criteria and an alternative design is being investigated.

\section{Plans for Next Quarter}

Mechanical design and analysis support for rotor components will be provided as needed.

\section{Technology Application}

The analysis work performed and subsequent design modifications resulted in designs being chosen for the end cap of the bore tube and the first- and second-stage bucket spoolies for the steam delivery system.

\section{Section 2.2.2.3.2 (GTFFTR) Wheel Forging Residual Stress Analysis}

\section{Objective}

The objective of this task is to determine the influence of residual stresses on overspeed design limits for $\mathrm{N} 706$ and $\mathrm{N} 718$ wheel forgings. Overspeed tests on a 7F first-stage wheel (IN706) indicated that there might be large residual stresses in the wheel forgings after heat treatment. These residual stresses may have an effect on fatigue life and will affect residual displacements. The effect on residual rabbet deflections is particularly important since this may affect rabbet opening/closure as well as rabbet loading and local plasticity. If residual stresses turn out to be significant in the ATS machine (IN718) as well, they will have to be included in the design calculations. The residual stress calculation will be done on the 7F wheel first to correlate the analysis with available test data. The procedure will then be applied to the ATS first-stage wheel. 


\section{Plans for Next Quarter}

This task has been completed.

\section{Technology Application}

These residual stresses will influence the deformations of the wheel during overspeed. If they are found to be significant, they will have to be included in the design calculations for the ATS turbine wheels.

\section{Section 2.2.2.3.3 (GTFFTR) Rotor Steam Circuit Analysis}

\section{Objective}

The objective of this task is to assess rotational and 3D effects on the rotor steam circuit components, whose performance is strongly dependent on these effects. The steam distribution into the buckets, for example, depends on the performance of the manifolds to ensure that the buckets are adequately cooled. Hydraulic losses can be better estimated when 3D effects are considered. In addition to these effects, the performance prediction of the rotor steam circuit is based on the assumption that all parallel branches of the circuit behave identically. Non-ideal design and operational features will result in deviations from this ideal performance, but the extent of these deviations and their ultimate impact on bucket cooling is not presently quantified.

The rotational and 3D effects will be assessed using computational fluid dynamics (NOVAK3D), and the results of the analyses will provide the basis for design modifications as necessary. The impact of branch-to-branch variations will be evaluated using an expanded version of the rotor steam circuit network model (solved by YFT).

\section{Progress for this Quarter}

Solid models of the bucket supply manifold generated by Unigraphics were meshed for computational fluid dynamics (CFD) computation using the unstructured-grid solver NOVAK3D. The models include a long section of the axial inlet tube and extensions for the spoolies to allow the flow to develop before boundary conditions are applied. In the early stages of the study, the buckets were not simulated. The current baseline design, the T-design, was evaluated first. It displayed significant flow maldistribution to the buckets. The next design, the delta-wing concept, showed a significant improvement in flow distribution. The presence of the buckets, however, was expected to introduce a corrective factor of significant importance.

Using ID analyses, the geometric characteristics of orifices exhibiting pressure drops equivalent to those found in the first- and second-stage buckets were established and the NOVAK3D grid was updated. The original T-shape supply manifold was analyzed again and the flow distribution showed deviations of less than $2 \%$ among the buckets. The maldistribution due to the return manifold was addressed next.

Because the actual return manifold design was not available at the beginning of $1 \mathrm{Q} 97$, the supply manifold CFD model, with appropriate boundary conditions, was used to estimate the flow maldistribution introduced by the combined effect of both supply and return manifolds. 
The results indicated a total bucket flow maldistribution of less than $1.5 \%$. Simultaneously, the definition of details in the supply and return manifolds was carried out using $1 \mathrm{D}$ analyses to assess trade-offs between performance and design robustness.

The results of the CFD and ID analyses were implemented in the design process and the supply and return manifold detail designs are nearly complete.

\section{Plans for Next Quarter}

The newly-defined designs of the supply and return manifolds will be analyzed using CFD to establish their combined effect on flow distribution into the buckets and confirm the original estimate. CFD analyses of the rotor inlet and the end caps that define the coupling between the radial tubes and the bore tube will be run .

\section{Technology Application}

The results of this task define the hydraulic performance of the overall steam distribution circuit and of the individual components it comprises. Performance predictions of various designs were used in trade-off studies to select the baseline concept of the overall steam distribution strategy and the specific design of the scroll and the supply and return manifolds. Sensitivity studies will help anticipate the system response to perturbations.

\section{Section 2.2.2.3.4 (GTFFTR) Turbine Rotor Shaft Temperature Analysis - \#2 Bearing Objective}

The objective of this task is to investigate design options that would result in a minimum temperature of the shaft surface in contact with oil and/or air oil mist, and a maximum thermal gradient in the area of the oil seals in the $\# 2$ bearing.

Allowable temperatures in the seal forward of the $9 \mathrm{H}$ turbine $\# 2$ bearing are limited due to the accelerated decomposition of lubricating oil at high temperatures. Thermal gradients are also limited in that uneven thermal expansion of the shaft will adversely affect seal clearances and performance.

\section{Plans for this Quarter}

This task has been completed.

\section{Technology Application}

All the design options evaluated in this study are being considered for ATS turbine rotor design in a detailed follow-up study using a fluid element analysis (FEA) approach to better simulate the heat transfer boundary conditions in the current modeling effort. 


\section{Section 2.2.2.3.5 (GTFFTB) Bucket Temperature Monitoring}

\section{Objective}

The objective of this task is to provide the steam-cooled rotor buckets with protection against a loss-of-steam-coolant event. The protection system will provide a timely signal enabling the turbine to be shut down with minimal damage.

\section{Progress for this Quarter}

Pyrometers were chosen as the primary means of steam-cooled bucket protection. Several other technologies were investigated (e.g., tracer leaks, vibrational signatures, steam pressures, and steam flow rates), but they were discarded in favor of monitoring the bucket temperatures using pyrometers attached to the outer casing of the turbine with a direct line-ofsight view of the buckets. Pyrometers offer significant advantages (1) they respond to the bucket parameter of most concern (i.e., the temperatures); (2) all the buckets in a stage come into the field of view of a single fixed pyrometer; and (3) the detection system has a rapid response time. Line-of-sight was recognized as the method of achieving long-term pyrometer stability. A test site was chosen to establish pyrometer durability/ reliability and controls data.

\section{Plans for Next Quarter}

Pyrometer tests will start. The design of hardware modifications required for line-of-site access to the buckets will be completed.

\section{Technology Application}

Pyrometers will be used in the ATS gas turbine to monitor steam-cooled turbine blade temperature during operation. This will allow for timely detection of insufficient steam coolant flow into the buckets.

\section{Section 2.2.2.4 (GTFFTB) Turbine Bucket Design}

\section{Objective}

The objective of this task is the design of buckets for the four rotating stages. The heat transfer and material databases for steam-cooled first- and second-stage buckets continue to expand and will be integrated concurrently with the design. Cooling passages will be sized consistent with manufacturing practicalities and the bucket life requirements. Flow variation and consistency will affect life calculations and will be considered. Current practices for thermomechanical steady-state and transient analyses, dynamics and vibration analysis (which can deal with anisotropy), and corrosion/oxidation analysis will apply throughout. Drawings and specifications will be developed in preparation for manufacturing.

\section{Progress for this Quarter}

Design of the $7 \mathrm{H}$ turbine buckets continued. Further work was done to model the internal and external heat transfer coefficients on the first-, second-, and third-stages. A great deal of effort went into refining the casting envelope to minimize overall bucket mass. Work continued on optimizing the third-stage tip shroud configuration. Detailed 2D and 3D analysis continued on the first- and second-stage dovetails as well as the third- and fourth-stage shanks. Casting 
trials were completed to assist in aft bucket material selection. Robust design activities continued with the development of response surfaces of low cycle fatigue (LCF) life as a function of various casting features for the $9 \mathrm{H}$ first-stage bucket.

Detailed design continued on all four bucket stages for the $9 \mathrm{H}$ turbine. Drawings were issued for post-cast operations at outside vendors. Tooling was completed for all bucket stages. Third-stage bucket casting trials were completed. First-stage bucket casting trials are almost complete. Production parts for the first ATS turbine are now in process for both of these stages. Fourth-stage bucket casting trials are almost complete; production will begin in midApril. Second-stage bucket casting trials began in February; production will begin in mid-May.

\section{Plans for Next Quarter}

Casting trials will be completed on all stages of $9 \mathrm{H}$ buckets. All stages will move into production for the first ATS turbine. Final machining and instrumentation drawings will be issued. The first production third-stage buckets will ship from the casting vendor to post-cast operation facilities. Post-cast processing trials and transient analyses will continue. Robust design activities will continue with the refinement of first-stage bucket response surfaces and the completion of preliminary second-stage bucket response surfaces.

Analysis and optimization of the $7 \mathrm{H}$ bucket designs will continue with a view to electronic data release for the various bucket stages in $3 \mathrm{Q} 97$ and $4 \mathrm{Q} 97$.

\section{Technology Application}

The design and development of turbine buckets are required for the ATS turbine to ensure that the buckets deliver power to the turbine shaft and to ensure that the buckets meet the stated part life requirements.

\section{Section 2.2.2.4.1 (GTFFTB) Wheel Dovetail Analysis - S1B and S2B \\ Objective}

The objective of this task is to perform 3D thermomechanical analyses of ATS gas turbine rotor dovetails, bolt holes, and steam cooling holes. The dovetails are highly stressed and, in addition, there are severe thermal gradients in the dovetail region. Detailed 3D stress analyses are required to ensure that the dovetails and the wheels meet design guidelines.

\section{Progress for this Quarter}

The 7H second-stage turbine wheel/bucket dovetail 3D steady-state thermal analysis was run successfully and evaluated. The thermomechanical analysis ran successfully and is currently being evaluated. Effective and first principle stresses were plotted for both mechanical and steady-state thermomechanical cases for critical areas in the turbine wheel as well as both the bucket and turbine wheel dovetails. Axial length plots were generated for the bucket and turbine wheel maximum fillet stresses and dovetail tang loading including the turbine wheel slot bottom. A 2D plane stress model is currently being generated to evaluated a mesh density factor to be applied to the 3D stress results. 
The 9H second-stage turbine wheel/bucket dovetail 3D steady-state thermal and thermomechanical analyses are currently being run.

\section{Plans for Next Quarter}

The $7 / 9 \mathrm{H}$ second-stage turbine wheel/bucket dovetail 3D steady-state thermal and thermomechanical analyses will be completed and evaluated. These analyses will include several sensitivities on blade loading, coverplate loading, and thermal boundary conditions. Studies will also be conducted to evaluate a similar dovetail in the first-stage using the same model.

\section{Technology Application}

The dovetails are highly stressed and, in addition, there are severe thermal gradients in the dovetail region. Detailed 3D stress analyses are required to ensure that the dovetails and the wheels meet design guidelines for the ATS turbine rotor.

\section{Section 2.2.2.4.2 (GTFFTB) 9H Tip Shroud Design Optimization - S3B and S4B}

\section{Objective}

The objective of this task is to optimize stresses and creep deflections in the $9 \mathrm{H}$ fourth-stage bucket shroud. A detailed 3D creep analysis is needed to ensure that the stresses are within the required limits for creep life.

\section{Progress for this Quarter}

The scope of this task was expanded to include the $9 \mathrm{H}$ third-stage bucket and analysis of a field-tested bucket for experimental confirmation. Work has begun on generating the fourthstage bucket model.

\section{Plans for Next Quarter}

Work will continue on developing the fourth-stage model. Analyses of the third-stage bucket will be correlated with field experience.

\section{Technology Application}

The redesigned shroud will be used in the $9 \mathrm{H}$ fourth-stage bucket design. This analysis methodology will be repeated for the $7 \mathrm{H}$ fourth-stage bucket.

\section{Section 2.2.2.4.3 (GTFFTB) Bucket Wide Grain Sensitivity Analysis}

\section{Objective}

The objective of this task is to show the effect on natural frequency of the variations in grain size and orientation of $9 \mathrm{H}$ fourth-stage buckets. If the variations in natural frequency can be shown to be non-critical, bucket yield can be improved.

\section{Plans for Next Quarter}

This task has been completed. 


\section{Technology Application}

The results of this study will be used on the ATS gas turbine design primarily as a means of improving bucket yield.

\section{Section 2.2.2.4.3.1 (GTFFTB) 9H Robust Design and Life Assessment - S1B}

\section{Objective}

The objective of this task is to develop design methods for buckets to minimize the influence of design and manufacturing variables. Statistical design methodology will be used to relax presently used worst case conditions (worst material, worst temperature, etc.) and develop capabilities to quickly assess bucket life.

\section{Progress for this Quarter}

A series of analyses was conducted in order to determine the effect of metal wall thickness variation and thermal barrier coating thickness variation on the low cycle fatigue (LCF) life of the buckets. The analyses involved expressing the variations as 3D cubic spline functions that modify the pressure side and suction side thickness profiles of the airfoil. A response surface of the results was generated that easily allows the prediction of LCF life for cases other than those analyzed by finite element techniques. Results showed that the current processing parameters will yield buckets with satisfactory lives.

Methods were developed to accurately debit LCF life for metallurgical defects noted during inspection of bucket castings.

\section{Plans for Next Quarter}

Work will continue on the robust design/life assessment of the first-stage bucket and will begin on the second-stage buckets.

\section{Technology Application}

The results of this study will be used on the ATS gas turbine in order to assess bucket performance and obtain optimized factor settings and statistical distributions of the critical-toquality criteria (CTQs) given the distributions of the factors. The results of this study will be used on the ATS gas turbine design primarily as a means of improving bucket yield.

\section{Section 2.2.2.4.4 (GTETIH) Bucket Tip Treatment Heat Transfer}

\section{Objective}

The bucket tip regions of the ATS turbine remain a critical design issue affecting both turbine performance and life. Since the blades utilize no external film cooling, a tip design must be verified that minimizes both the tip hot gas leakage and the tip external heat loading, while also providing some shroud rub protection for the internal steam-cooling circuit. Standard squealer tip geometries are thought to provide inadequate rub protection and can be difficult to cool without film, while a plain tip geometry will not provide adequate leakage sealing. 
This task continues design verification and design improvement for the first- and second-stage blade tips. The Blade Tip Heat Transfer Cascade at Texas A\&M University will be used with new or modified blade tip geometries to design and verify the appropriate tip heat transfer and seal arrangements in conjunction with manufacturing and cooling requirements. Specifically, this task will determine the external heat transfer coefficient distributions on the blade tip and on the airfoil surface near the blade tip using transient liquid crystal techniques.

\section{Progress for this Quarter}

During 1Q97, Texas A\&M concentrated on completing the required test scope from 1996, including tip heat transfer for two geometries with high and low freestream turbulence intensity, near tip surface heat transfer, shroud pressure measurements, and freestream turbulence intensity measurements. Although Texas A\&M provided blade tip data for both the plain tip and the rub-strip tip geometries at low and high freestream turbulence intensity levels, these data have yet to be shown to be repeatable and will not be reported until they are deemed reliable. In particular, issues of both test-to-test flow rates and liquid crystal in-situ calibration were raised with Texas A\&M.

Texas A\&M performed the shroud pressure field measurements for the plain and rub-strip tip geometries, but has not summarized the results for transmission to GE. Texas A\&M has not yet repeated the previous blade tip heat transfer measurements to demonstrate repeatability and reliability. Texas A\&M was informed that they will not receive funds for the 1997 followon tasks until GE is satisfied with the reliability of their data and the test procedures they employ (i.e., the rigor of their procedure, not the methodology).

\section{Plans for Next Quarter}

The work scope for $2 \mathrm{Q} 97$ remains unchanged. Texas A\&M intends to provide full measurements of the shroud surface pressure fields for both blade tip geometries begun in 1996 , as well as hot-wire turbulence intensity measurements at the inlet to the cascade. Texas A\&M will then repeat the blade tip heat transfer measurements for comparison to earlier data and demonstration of repeatability. Upon satisfactory completion of this work, with demonstration of good test repeatability, Texas A\&M will begin to collect blade tip data on several modified tip geometries that seek to improve upon leakage sealing and heat load reduction.

\section{Technology Application}

The results from the testing performed under this task will be used directly in the design of the first- and second-stage bucket tips to improve tip performance and provide more accurate assessments of tip life. Tip geometries shown to have lower heat loads or less gap leakage, or both, will be incorporated into the design process.

\section{Section 2.2.2.4.5 (GTFFTB) Air/Steam Coolant Transition Analysis - S1B and S2B}

\section{Objective}

The objective of this task is to determine the time required for switching from air cooling to steam cooling to keep thermal stresses in the $9 \mathrm{H}$ first-stage and second-stage buckets within 
acceptable levels. Three-dimensional transient thermomechanical analyses of the first- and second-stage buckets will be run during the transition from air to steam cooling. Predicted temperature and stress responses will be used to evaluate the effect of the coolant change on the bucket lives and to recommend control system modifications, if necessary.

\section{Progress for this Quarter}

The ANSYS/LFE model of the first-stage bucket was updated to include recent platform cooling modifications. A preliminary steady-state analysis of the first-stage bucket at full speed, full load (FSFL) conditions was run to include the effects of recent $9 \mathrm{H}$ rotor cooling configuration changes. These results are being benchmarked against design calculations and will provide heat transfer boundary conditions for the robust design analyses.

The ANSYS/LFE model of the first-stage bucket was updated to include recent platform cooling and geometric modifications. Steady-state analyses of the first-stage bucket at FSFL conditions were run to generate boundary conditions for robust design analyses.

The ANSYS/LFE model was also used to predict the effect of loss of steam cooling on the bucket. Steady-state and transient thermomechanical analyses were run to evaluate the impact of reduced coolant flow on bucket performance, and to estimate the required shutdown time in the event of a total loss of coolant.

The ANSYS/LFE model of the second-stage bucket was initiated. Surface elements were created in the bucket internal cooling passages, and the LFE elements are being generated. The ANSYS/LFE model of the second-stage bucket airfoil and platform is nearly complete and is being benchmarked against the design basis ANSYS model at FSFL conditions.

\section{Plans for Next Quarter}

Steady-state and transient thermal and structural analyses of air-to-steam transition for firstand second-stage buckets will be run.

\section{Technology Application}

The air-to-steam transition requirements during startup will have to be controlled so that the LCF life of the buckets will meet design guidelines. If the LCF life is too short with the present control plan, the air-to-steam transition rate will have to be changed to put the LCF life at an acceptable level.

\section{Section 2.2.2.4.6 (GTETEH) External Heat Transfer - S1B}

\section{Objective}

The ATS turbine first-stage bucket is highly loaded both aerodynamically and thermally. It is crucial that the external heat loading for this component be predicted accurately. A nonconservative design heat load may result in a low life part design, while a too conservative heat load will lead to over-utilization of steam coolant. As the heat load distribution is a major contributor to the bucket cooling design and its effectiveness, an accurate determination of the external heat transfer distribution is required to minimize the impact of other variable factors in the design. 
This task will provide external heat transfer coefficient distributions for the pitch section of the ATS turbine first-stage bucket. Cascade slave hardware will be manufactured by CRD for installation into the Transonic Blade Cascade facility at NASA Lewis Research Center, Cleveland. NASA will perform flow and heat transfer tests with a smooth airfoil and report heat transfer distributions at the design Reynolds number. Rough surface testing is optional in this program. This task is being carried out in conjunction with CRD's Research Alliance with NASA Lewis (no funds are exchanged in this Alliance).

\section{Progress for this Quarter}

During this period, the aerodynamic definition of the blade section was received from GEPS and forwarded to the CRD machine shop for layout and materials estimation. The stainless steel and aluminum for the slave hardware were ordered, and drawings were begun for the fabrication of 15 airfoils, 2 with static pressure instrumentation. The blade coordinates were transmitted to NASA for incorporation into their cascade drawings and location of the fixturing pins.

\section{Plans for Next Quarter}

Drawings for the pressure-instrumented airfoils will be completed. The duplicate slave airfoils will be machined and the aluminum blade mold fabricated. NASA will be contacted to determine the appropriate operating conditions for this blade design within the limitations of their facility.

\section{Technology Application}

The results of this task will be used to verify or alter the predicted design external heat loading for the first-stage bucket. Where the experimental results deviate significantly from the design predictions, changes in the blade coolant flow can be made to achieve a more efficient design.

\section{Section 2.2.2.5 (GTFFTS) Turbine Stator Design}

\section{Objective}

The inner and outer turbine shells will be designed, including a turbine stator cooling system to provide rotor/stator clearance control. A closed circuit coolant delivery and return system for the turbine flowpath stator components will be designed. Component, sub-assembly, and assembly flow tests will be incorporated concurrently. Implications for handling equipment (crane and manipulators ) will be included in design considerations.

Steam-cooled turbine nozzles will be designed. Thermomechanical transient and steady-state analyses will be run to determine parts lives. Material, manufacturing, and heat transfer database expansion is planned and will be integrated concurrently.

Shrouds will be designed. Sealing systems will be selected for minimum leakage. Thermal and structural analysis of equiaxed or anisotropic materials will be applied as appropriate.

Calculations will be made of all flow in the cooling systems, including leakage flows, to support performance, thrust balance, and component temperature calculations. 
Design of hot-gas-path seals will be based on laboratory tests. Seals developed for transitionpiece-to-nozzle segment and intersegment interfaces will be evaluated in cascade tests. Both sealing and wear performance will be assessed. Manufacturing drawings and specifications will be produced.

\section{Progress for this Quarter}

The detailed turbine nozzles aerodynamic design is complete and a formal aero design review was completed. The concepts for cooling and sealing of the nozzles were defined and preliminary 2D stress and heat transfer analysis was run. Conceptual design reviews of the nozzles were completed. Interfaces between the components are being defined. SLA models of the nozzles were made.

\section{Plans for Next Quarter}

Detailed heat transfer and stress analysis of the turbine nozzles and shrouds will be completed. Detailed flow analysis will be run to allow final definition of the cooling flow circuits. Nozzle covers and impingement inserts will be defined and their fit-up verified through 3D modeling. An overall detailed leakage/flow model will be used to optimize component sealing. Component interfaces will be completed.

\section{Technology Application}

The turbine stator analysis and design effort defined the basis for the $7 \mathrm{H}$ and $9 \mathrm{H}$ production hardware.

\section{Section 2.2.2.5.1 (GTFFTS) Turbine Stator Robust Design}

\section{Objective}

The objective of this work is to develop and apply robust design methods for the development of steam-cooled components of the advanced gas turbine. The goal of this effort is to achieve high standards of performance quality and reliability for these components by performing the following tasks during the product development cycle: (1) apply, and develop as needed, the robust design methodology to first- and second-stage nozzles; (2) apply the robust design methodology to some of the steam- and air-cooled stator components (e.g., first-stage shroud and turbine inner shell); (3) provide consulting and support for applying the robust design methodology to some of the critical rotor components (e.g., manifold, steam tube bushings, and spoolie); (4) provide consulting and support for integration of design, manufacturing, and assembly; and (5) train the GEPS staff on the concepts, methods, and tools for achieving robust design.

A "robust design" is a design that satisfies the product performance requirements in an optimal manner and also exhibits minimal sensitivity to variabilities arising from various sources, such as manufacturing processes and tolerances, material behavior, operating environment, in-service damage, and maintenance and repairs. The methodology consists of the following key steps: (1) identification of critical-to-quality (CTQ) characteristics, key control parameters (KCPs), and key noise parameters (KNPs); (2) definition of the Design of Experiment (DOE) matrices for KCPs and KNPs; (3) execution of the DOE matrices through 
analysis, testing, prototyping, and/or manufacturing; (4) statistical analysis of the DOE data to develop response surfaces, (5) optimization using response surfaces to determine optimal $\mathrm{KCPs}$ that meet the CTQ requirements and minimize sensitivity to variations; (6) performing Monte Carlo analysis to quantify the likelihood of meeting CTQ requirements under various noise conditions; (7) improving the part's producibility and assembly by specifying wide manufacturing and assembly tolerances; and (8) validating the design developed through analysis and/or testing. The methodology was demonstrated successfully on a number of reallife complex applications and is being applied in the present project to steam-cooled components of the ATS gas turbines.

\section{Progress for this Quarter}

Robust design efforts were focused on (1) generating new finite element models (FEMs); (2) parameterizing and updating the existing FEMs; (3) developing robust design formulations by identifying performance critical-to-quality characteristics (CTQs), key control parameters (KCPs), and key noise parameters (KNPs); (4) developing design of experiments (DOE) matrices and executing them through finite element analyses; (5) carrying out statistical analysis of the DOE results, developing response surfaces, and optimizing the CTQs for their means and variances; (6) documenting progress made in 1996; and (7) providing consulting services to GEPS staff on robust design.

\section{First-Stage Nozzle}

Robust design analysis of the first-stage nozzle was run. Sensitivities of the low cycle fatigue (LCF) life relative to manufacturing tolerances were minimized. The FEM was updated to include the latest geometry, heat transfer boundary conditions, and material properties. Robust design parameters and a DOE matrix for probabilistic/Monte Carlo analysis were completed, and the process of making the analysis runs was automated. Several verification runs were completed. Analysis of the DOE runs will start this month. A strategy for LCF life assessment of the as-cast parts to be received from the vendor was developed using the response surface approach.

\section{Second-Stage Nozzle}

A FEM comprising airfoil, inner and outer sidewalls, inner and outer fillets, and hook portion was developed. FEMs of individual singlets were combined to create a doublet per design requirements. Boundary conditions were applied to the FEM. Thermal analysis of the model was run to calculate temperature distribution in the nozzle.

\section{First-Stage Shroud}

Macros were developed to update the FEM geometry boundary conditions and other analysis parameters as required for DOE analyses. Robust design parameters and a DOE matrix were defined.

\section{Rotor Components}

Spoolie Design: Robust design analysis was developed. A DOE matrix and parameters were defined. Analysis of the DOE data was run jointly with the GE Gas Turbine (GEGT) staff. DOE runs resulted in reduced stresses, thereby improving part life. 
Steam Tube Bushings: Several DOE matrices and their parameters were defined and executed. As a result of the analysis, stresses were significantly reduced, thereby improving part life.

Manifold: $A$ DOE matrix and parameters were defined. Analysis runs were performed. The results are being used in evolving the design concept/configuration.

Flanges: $A$ DOE matrix and parameters were defined using mixture design concepts. Analysis of the DOE runs were performed by the GEGT staff. The results are being analyzed to minimize the flange openings.

Turbine Inner Shell

A robust design approach was defined. A DOE matrix and the parameters were defined. The present focus is on performing the DOE runs.

\section{Plans for Next Quarter}

\section{First-Stage Nozzle}

Analysis runs for the probabilistic/Monte Carlo analysis will be performed. Results will be analyzed and response surfaces will be developed. Monte Carlo analysis will be performed using the response surfaces and the FPI code. DOE matrix and parameters will be completed for the life assessment study. DOE runs will be performed, results will be analyzed, response surfaces will be developed and used in assessing the LCF life of as-cast parts received from the vendor. The FEM will be updated to incorporate the latest design updates for a follow-on robust design analysis.

\section{Second-Stage Nozzle}

The FEM will be completed by adding the cover. Boundary conditions and loads will be applied, and verification runs will be performed. The robust design approach will be completed, a DOE matrix and parameters will be defined, and robust design as well as the Monte Carlo analysis will be carried out.

\section{First-Stage-Shroud}

DOE runs will be completed, results will be analyzed, response surfaces will be developed, and robust design and Monte Carlo analysis will be performed.

\section{Rotor Components}

DOE results for the manifold and flanges will be analyzed. Designs will be optimized to meet the CTQ requirements. Additional DOEs will be defined to improve the design further. Variabilities/uncertainties will be included in the next study to minimize sensitivities of performance CTQs.

\section{Turbine Inner Shell}

DOE runs will be executed, statistical analysis of the data obtained will be carried out to develop response surfaces, and optimization will be performed to minimize sensitivities. 


\section{Technology Application}

Results will be used in the development of part drawings in terms of nominal dimensions and manufacturing tolerances, LCF life assessment of as-cast parts to be received from vendors, quantifying the confidence level in meeting the CTQ requirements under various sources of variations, and improving part producibility by widening manufacturing tolerances.

\section{Section 2.2.2.6 (GTFFST) Structures Design}

\section{Objective}

The objective of this task is to design the exhaust frame and diffusers, steam gland, and aft bearing housing. Instrumentation and test plans for component model, factory, and field testing will be prepared.

\section{Progress for this Quarter}

\section{Exhaust Frame and Diffuser}

The exhaust frame and diffuser supplier completed a material layout and began purchasing material to produce the first exhaust frame and diffusers. Detailed fabrication drawings of the radiation shields based on input from the vendor and the GE manufacturing engineer were completed. The machining drawing release of the exhaust frame is in the review process. A failure modes and effects analysis (FMEA) was undertaken for the exhaust frame cooling circuit and adjacent cavities to obtain a detailed evaluation that could be used to identify methods for lowering system risk. A cooling circuit analysis with various operating conditions and sensitivities to off-design conditions was examined, and methods were identified for adjusting the flow circuit based on actual frame flow test results. The 3D finite element analysis (FEA) of the exhaust frame and forward diffuser was completed for all mechanical and steady-state thermal effects as well as for transient thermal loads and stresses for final lifing estimates. A preliminary instrumentation plan for design verification on first unit test was completed, including an evaluation to remove/support the telemetry system for rotating instrumentation lead-out.

Aft diffuser concept analysis was completed, and preliminary tests were run at CRD on the aero/performance effects of internal insulation "hangers" in the flow path.

\section{Steam Gland}

The casting release review of the steam gland was completed, and the vendor started the casting pattern for the first unit. A revised CAD 3D solid model of the steam gland that incorporates casting pattern/producibility comments for final lifing predictions was completed. A 3D solid finite element model (FEM) of the steam gland current geometry for deflection and detail stress (for low cycle fatigue [LCF] analysis) is complete. Minor geometry adjustments to the aft two seal designs, the "false flange" at top and bottom, etc., were completed to ensure that deflection and lifing concerns are addressed. Machining drawings for the steam gland were issued. Detailed labyrinth seal drawings were completed, including modifications to reduce swirl interaction features. 


\section{\#2 Bearing Housing}

The casting vendor has nearly completed the casting pattern for the first unit. A hold was put on this part during 1Q97 to ensure that the interfacing turbine rotor surfaces could meet the boundary conditions to make the air and oil seals acceptable at the forward end. Flow analysis of the oil and air seals is complete with the assumptions of holding rotor temperature and delta temperature across seals to within GE experience levels. The machining drawing was issued. Thermal and flow analysis will continue on the heat rejection at the bearing due to steam supply through the rotor bore and on acceptable deflections. First unit test instrumentation was identified and the modification machining drawing was started.

\section{Plans for Next Quarter}

\section{Exhaust Frame and Diffuser}

Structural, thermal, and cooling flow analyses and the machining drawings of the $9 \mathrm{H}$ exhaust frame and forward diffuser, \#2 bearing housing, and the steam gland are almost complete with focus shifting to final assembly and instrumentation releases. A unit assembly planning meeting will be held in Greenville, SC, to develop tooling, accessibility, and maintainability methods with assembly personnel. The study of aft diffuser flow path internal-insulation hangers will be completed at CRD and will determine the final path to pursue for the outer diffuser design (internally vs. externally insulated).

Test of the steam pipes in the diffuser flow path will be completed at CRD for a 1/9-scale model to properly model the effects of pipe vortex shedding and its possible impact on performance. Testing of the possible design configuration of the aft diffuser and its interfaces to the high pressure recovery aft duct will start.

\section{Steam Gland}

The assembly drawings will be issued, and the vendor will have completed the casting first piece qualification (FPQ) and shipment to the final machining vendor. The steam gland design will be examined for possible cost reduction/design optimization using brush seals in place of the labyrinth seals.

\section{\#2 Bearing Housing}

The \#2 bearing housing assembly drawings will be completed. The bearing housing casting vendor will complete the casting pattern and the first pour will be completed. All interfacing conditions with the rotor, bearings, etc. will be completed for normal conditions and offdesign conditions. Bearing instrumentation placement and routing will be completed using the mockup.

\section{Technology Application}

The analysis and design effort establish the basis for the $7 \mathrm{H}$ and $9 \mathrm{H}$ structure designs. 


\section{Section 2.2.2.6.1 (GTFFSTEF) Exhaust Diffuser Performance}

\section{Objective}

The requirements for the ATS gas turbine exhaust diffuser include (1) improved baseload pressure recovery performance compared with earlier GE exhaust diffuser designs and (2) operation without acoustic resonance at any operating point of the gas turbine. The objectives of this task are to test potential ATS gas turbine exhaust diffuser geometries for pressure recovery performance and to verify that the design selected does not excite acoustic resonances.

The test program includes the installation and test of a scale model diffuser with flow path geometries and components compatible with the ATS gas turbine. Specifically, the cost-saving idea of internal insulation will require axial ribs in the walls of the diffuser flow path. Impact on pressure recovery will be measured. Several other tests will be performed, each with the aim of maximizing performance. These tests include examining variations in flow path, centerbody length and termination shape, steam pipe locations and fairings, and other diffuser features that affect performance. The final exhaust diffuser design will be tested to verify that no acoustic resonances are excited, particularly at full speed, no load (FSNL) conditions.

\section{Progress for this Quarter}

A baseline scale model exhaust diffuser was instrumented for pressure recovery measurements. It was tested at both FSNL and full speed, full load (FSFL) conditions. It is currently being reconfigured with internal surface strips to evaluate the effect of internal insulation on diffuser performance for the ATS gas turbine.

\section{Plans for Next Quarter}

A new scale model of the ATS gas turbine exhaust diffuser and exhaust duct will be designed and built. It will be instrumented both for pressure recovery and for detection of acoustic resonances. Its performance will be mapped over a variety of inlet swirl angles and Mach numbers to verify that the design meets performance objectives.

\section{Technology Application}

The results from this series of scale-model gas turbine exhaust diffuser tests will be used to establish several diffuser design features. One of these features is the feasibility of an internally insulated exhaust frame, a less expensive option than external insulation. Data will be used to design a diffuser with the required pressure recovery, enhancing the overall combined-cycle plant efficiency. These tests will verify that the final design is free from acoustic resonances.

\section{Section 2.2.2.6.2 (GTFFST) Steam Box CFD Analysis}

\section{Objective}

The objective of this task is the design of a steam delivery system as part of the $9 \mathrm{H} / 7 \mathrm{H}$ steam cooling design. A steam gland is being designed to bring the cooling steam from a stationary inlet pipe onboard a rotating shaft. Steam will enter the steam gland through an axial inlet pipe. The pipe turns $90^{\circ}$ so that the resulting flow is traveling tangent to the rotor shaft and 
into an inlet scroll. The inlet scroll cross-sectional area is sized to match the steam velocity to the rotor tangential velocity. As the steam travels around the scroll circumferentially, some steam is being extracted into rotor slots. A 3D computational fluid dynamics (CFD) analysis is required to define the appropriate geometry of the steam gland inlet scroll that will result in a nearly uniform radial outflow from the scroll circumference.

\section{Progress for this Quarter}

To confirm the results obtained thus far with NOVAK3D and to assess the effect of the constant exit static pressure assumption required by NOVAK3D, TfC (another CFD code) was used to solve both the original and "continuous scroll outlet" concepts. Both TfC and NOVAK predict a better performance for the modified design, as measured by the standard deviation of the velocity profiles about their mean. Although the comparison between the NOVAK and TfC solutions is satisfactory, the root of the differences was investigated and found to be the differences in the flow predictions in the elbow region of the design. The NOVAK flow pattern indicates a stronger recirculation downstream of the elbow than predicted by TfC. The effect of the exit static pressure on the solution was evaluated by running TfC in the "uniform exit pressure" mode (similar to NOVAK's) and then again with the "non-uniform exit pressure" option. The results of this effort were documented and presented in a design review of the steam gland design. No outstanding issues in this area were identified. The proposed continuous scroll outlet concept is the current baseline design.

\section{Plans for Next Quarter}

This task has been completed.

\section{Technology Application}

The results of this study have had an impact on the design of the scroll geometry and confirmed its proper performance in meeting the desired uniform flow distribution. The analysis of the entrance to the rotor serves three purposes: it incorporates rotational effects and confirms the 1D analyses of the YFT study of the steam distribution system; it points to the relative insensitivity of the current design to variation in the inlet conditions of the flow; and, with the prediction of the relative swirl angle, obstacles in the annular passage will be designed to be aligned with the incoming steam.

\section{Section 2.2.2.7 (GTFFMS) Mechanical System Design}

\section{Objective}

The objective of this task is to perform system level studies to optimize cost and performance. Performance, cost, weight, and other system level integration issues will be monitored and tracked. A flange-to-flange cross-section drawing will be maintained, and all mechanical interfaces will be controlled. All gas turbine systems, as well as the technical requirements for accessories, will be defined and specified.

\section{Progress for this Quarter}

System level studies continue to be performed to optimize cost, performance, weight, size, maintainability, reliability, and manufacturability. Performance, cost, weight, and other system 
level and integration issues are being monitored and tracked. The systems review team, which includes engineering, manufacturing, sourcing, and maintainability personnel, continues to meet to review the merit of system issues, and determine whether incorporation of ideas meets system goals such as cost, schedule, and performance.

The maintainability, reliability, and serviceability team continues to work to ensure that all of the "lessons learned" for field operation are being incorporated into the $9 \mathrm{H} / 7 \mathrm{H}$ design.

Performance estimations for both the $7 \mathrm{H}$ and $9 \mathrm{H}$ were updated, reflecting the current design configuration and assumptions. Machine cost data were updated as the designs mature, enabling more accurate estimates. System interfaces for the $9 \mathrm{H}$ were completed. Both $9 \mathrm{H}$ and $7 \mathrm{H}$ integrated schedules were updated to reflect current cycles and deliverables. A Risk Workout was held to update risk avoidance plans and accomplishments.

\section{Plans for Next Quarter}

System studies to optimize cost and performance will continue. Progress in cost, risk, schedule, and performance of the gas turbine design and manufacturing effort will be monitored and tracked. The component integration effort to establish and document interfaces will continue. The $7 \mathrm{H}$ engineering milestone schedule will be integrated with the manufacturing schedule and released as a working document.

\section{Section 2.2.2.7.1 (GTFFMS) Transient Gas Turbine Cycle Platform Evaluation}

\section{Objective}

The objective of this task is to evaluate computer platform and software options to best support the integration of a transient gas turbine model into a combined cycle simulation.

The current state of transient modeling for the ATS machine was reviewed with GEPG Engineering and was compared to the GEAE approach. From this brief study it was determined that a new transient model of the ATS machine was necessary in order to reflect more accurately its aero and thermal behavior. This work will assist GEPG Engineering in developing the new transient model with a steady-state accuracy goal of approximately $\pm 1 \%$. The model will be designed to be included in overall power plant simulations.

\section{Progress for This Quarter}

The work is progressing on a track that is different from the recommendations reported for $4 Q 96$ and uses the steady-state ATS gas turbine cycle model as a basis for the transient model instead of the recommended GEAE LM2500 component level model. Work began on using the LM2500 as recommended, but it was found that the model would need major modification and a great deal of learning would be required before it could be used effectively by the modeling community in GEPS.

In a natural progression of building on work from $4 \mathrm{Q} 96$, the steady-state cycle model was converted to function as a subroutine in the overall combined cycle transient simulation with the appropriate interface variables. Several obvious steps were taken to speed up the calculations so that the model in its current form would satisfy the non-real-time computation speed requirements. The model was transferred to GEPS's Combined Cycle Systems 
Technology and Advanced Controls System Engineering, and operation was demonstrated in each of their simulations by a transient load change from $100 \%$ load to $50 \%$ and back to $100 \%$ over a 2000 -second time period. The model computation time was demonstrated to be adequate (about 0.1 second) for the non-real-time model in its current form. A speed-up to approximately 0.003 second is required to satisfy the real time requirements. Means of speeding up the calculations were identified but have not been implemented. It is not certain that the real time computation requirement can be met with the detailed model, and a reduced detailed model may yet be required. In any event, the more detailed model is required as a benchmark for comparison of results.

\section{Plans for Next Quarter}

A model that represents the time-temperature history of critical metal parts is being developed and will be completed in steps in $2 \mathrm{Q} 97$ and $3 \mathrm{Q} 97$. A simple rotor metal temperature model was created in 1Q97 and included in the current gas turbine model. The goal is to model the metal temperature of key metal parts and create a stress and clearance model that utilizes the temperatures. The clearance and stress models are to be developed in 3Q97 and 4Q97.

Steps to speed up the model will be implemented; calculations will be extended to allow operation down to $5 \mathrm{rpm}$ and zero fuel flow. The model is required to operate from startup to full load and at overspeed.

\section{Technology Application}

This transient model will be used with detailed overall simulations of the plant gas and steam processes. This overall simulation will be used to verify the performance of the ATS system and to minimize the risk of any problems.

\section{Section 2.2.2.8 (GTFFPP) On-Base and External Piping Design}

\section{Objective}

The objective of this task is to design piping for fuel, air, steam, water, and oil transfer. A turbine base will also be designed for securing the ATS gas turbine to the foundation.

\section{Progress for this Quarter}

A conceptual design review of the $9 \mathrm{H}$ turbine base was held during $1 \mathrm{Q} 97$. No technical issues were found. The only major open issue on the turbine base at this time is completion of the base-to-turbine interfaces.

A conceptual design review was held for cooling and sealing air, variable guide vane (VGV), and fire protection. Several action items were generated for each with a plan put in place for implementation. Conceptual design for the balance of the piping systems continued.

\section{Plans for Next Quarter}

A turbine base final design review is planned for 2 Q97. System requirements will continue to be addressed and reviewed. Work on conceptual piping designs will continue with final design reviews planned for cooling and sealing air and VGV piping systems. 


\section{Technology Application}

The turbine base and piping designs require the consideration of new ideas in this technology application. The turbine base must be capable of handling and transferring much larger loads than in previous gas turbine designs. This requirement is complicated by the limited space available to the turbine base because of the machine shipping envelope, the increased number of systems requiring piping for fluid transport, the piping size and quantity, and the foundation interface limits. In summary, the piping design challenge is driven by the increase in size and quantity of fluid systems support required by the turbine and the limited space around it. These piping designs demand creative ideas in packaging and hardware selection.

\section{Section 2.2.2.9 (GTFFTT) Instrumentation and Test}

\section{Objective}

The objective of this task is to instrument and conduct field tests that validate the ATS gas turbine design for mechanical integrity and operating performance of the unit and establish emissions performance. Test plans will be formulated and instrumentation will be specified. Compressor and turbine rotor telemetry systems will be developed and acquired.

\section{Progress for this Quarter}

The telemetry system approach was selected as a front-end system for transmitting signals from all sensors mounted on the rotor including the compressor and turbine sections. The telemetry systems will be mounted in the load coupling. Work started on the instrumentation drawings, including compressor rotor, turbine buckets, nozzles, and casings.

\section{Plans for Next Quarter}

A final decision will be made on the number of sensors for the entire flange-to-flange gas turbine unit and power plant components. Instrumentation drawings and telemetry system design will be continued.

\section{Technology Application}

These are test plans to establish the instrumentation requirements for $7 \mathrm{H}$ and $9 \mathrm{H}$ full speed, no load (FSNL) and full speed, full load (FSFL) tests.

\section{Section 2.2.3 (GTET) Technology Validation}

The overall objective of this task is to provide confirmation of critical component design and technology. The validations include hot gas path component testing, sub-scale compressor testing, steam purity test trials, and rotational heat transfer testing. Technology enhancements that are not required for the first machine design but will be critical for future ATS advances in performance, reliability, and costs will be conducted. 
Section 2.2.3.1 (GTETNC) S1N Design

\section{Section 2.2.3.1.1 (GTETNC) Nozzle Cascade CFD Analysis}

\section{Objective}

The objective of this task is to apply a fully viscous 3D computational fluid dynamics (CFD) analysis to predict the flow and aid in the generation of heat transfer boundary conditions for the first-stage Nozzle Cascade Test. Such a validated CFD tool then becomes the vehicle to apply the Nozzle Cascade Test data to the actual machine design problem.

\section{Plans for Next Quarter}

This task has been completed.

\section{Technology Application}

The validation of NOVAK3D predictive capabilities provides a valuable tool to evaluate the impact of design modifications and off-design performance of ATS nozzles in particular. It also contributes to a more realistic calculation of heat transfer coefficients and consequently enhances the heat transfer predictions in complex geometries.

\section{Section 2.2.3.1.2 (GTETEH) Combustion-Generated Flow Effects on Heat Transfer}

\section{Objective}

The objective of this task is to evaluate the freestream turbulence intensity incident upon the ATS first-stage nozzle airfoil, and the effect of this turbulence level on the airfoil heat load. This turbulence intensity level and its character have a major and direct bearing on the heat load for the nozzle airfoil and endwall.

\section{Plans for Next Quarter}

This task has been completed.

\section{Technology Application}

The ATS cascade test results were incorporated directly into the ATS first-stage nozzle design. Comparison of results with both high-turbulence-generating perforated plates and a DLN combustor system cold-flow mockup verified the applicability to design of heat transfer results from the former method.

\section{Section 2.2.3.2 (GTETRS) Rotor Steam Transfer}

\section{Objective}

For stable cooling of the turbine buckets, static flow tests will be conducted to validate the steam flows in the circuit to and from the buckets, through the rotor. These will establish flow losses for the unique components in the steam delivery circuit. 


\section{Progress for this Quarter}

Flow testing of the rotor inlet geometry is now complete, and the preferred geometry to minimize inlet pressure losses was identified. Flow testing of spoolies is complete for the manifold-to-bucket spoolies, and pressure losses were determined.

\section{Plans for Next Quarter}

At the end of the entry tube the steam is turned through $90^{\circ}$ and split from a single path to multiple paths. The flow losses for this component of the rotor steam circuit will be tested in 2 Q97. Pressure losses will be evaluated for the larger spoolies used in other areas of the flow system.

\section{Technology Application}

Rotor steam transfer tests are used to evaluate the design optimum for the $7 \mathrm{H}$ and $9 \mathrm{H}$ turbine bucket cooling.

\section{Section 2.2.3.3 (GTETSE) Rotor-Bucket Steam Transfer Spoolie}

\section{Objective}

Rotating air test rig tests will be performed to validate the steam transfer spoolie design concept. (Spoolies are the hollow, spool-shaped ducts that bridge the gap between the steam delivery channels in the turbine rotor and cooling channels in the buckets.) A stationary steam test rig will be used for evaluation of durability and alignment effects on leakage.

\section{Progress for this Quarter}

The new test rig is now complete, enabling wear testing of larger spoolies at simulated engine operating conditions of temperature, pressure, G-field, and environment (steam). Separately, wear coating screening tests started for a number of candidate coatings to determine whether other coatings might be better suited for this application.

\section{Plans for Next Reporting Period}

Several tests will begin to investigate wear rates in steam and air environments, concentrating initially on the geometry effects of larger diameter spoolies. Initial coating screening tests will be completed, identifying alternative coating candidates.

\section{Technology Application}

These tests will validate the rotor bucket steam transfer spoolie design.

\section{Section 2.2.3.4 (GTETRH) Rotational Heat Transfer}

\section{Section 2.2.3.4.1 (GTETRH) Rotational Effects on Bucket Mixing Ribs}

\section{Objective}

The addition of mixing ribs to turbine blade radial cooling passages was found to provide a more robust thermal design, without the severe reduction in performance measured 
previously, when evaluated in sub-scale models at low Reynolds numbers. Since this design improvement is scheduled for use in the ATS gas turbine, design data that incorporate this change need to be obtained at full-scale conditions in the operating range of interest.

A full-scale turbulated test passage of the appropriate aspect ratio will be constructed that will be identical to the one tested previously except for the addition of the new mixing rib geometry. This passage will be evaluated in the full-scale rotational test rig over the range of dimensionless parameters present in the ATS gas turbine.

\section{Progress for this Quarter}

The full-scale test passage and assembly were designed and drafting was completed. Shop work on the long-term items was initiated in mid-February. Welded and brazed test duct construction trials were run to determine the best technique for accurate duct construction. These trial ducts do not have turbulators and mixing ribs. The turbulator and mixing rib design was reviewed with GEPS Engineering.

\section{Plans for Next Quarter}

The construction and installation of the test duct are scheduled for completion at the end of 2Q97. If no further machining time is lost, this schedule should be met. It should be noted that, provided the needed data are available by the end of October, there will be enough time to make any necessary adjustments in the turbine blade passage turbulator or rib configuration.

\section{Technology Application}

The new turbulator and rib design, which has to-date only been demonstrated in small-scale tests, is being employed to reduce the bucket cost and to yield a more robust design with improved performance at high Buoyancy numbers. This design will be validated by the fullscale data to be generated under this task.

\section{Section 2.2.3.4.2 (GTETRH) Bucket Cooling Circuit Rotational Pressure Drop Test}

\section{Objective}

The objective of this task is to determine the effect of rotation on the pressure drop in a radial bucket cooling passage. The computational fluid dynamics (CFD) computations of the effect of rotation on bucket cooling passage heat transfer and pressure drop indicate a significant effect of the Buoyancy number on pressure drop. Since the bucket pressure drop is a major fraction of the total system pressure drop involving the coolant, it was deemed necessary to measure this effect using the full-scale test rig.

The high aspect ratio turbulated duct assembly was instrumented to measure the pressure drop between the inlet and outlet manifolds. Appropriate heaters were employed on the pressure measurement lines to avoid condensation of the working fluid and to minimize the density corrections required due to temperature differences between the measurement lines and the test duct. This allowed the differential pressure transducer to be mounted near the rotational axis, where no transducer correction for centrifugal effects was required. The pressure drop for both outflow and radial inflow was measured. 


\section{Plans for Next Quarter}

This task has been completed.

\section{Technology Application}

The new pressure drop correlation, which includes the effect of the Buoyancy number, is now in use in the evaluation of alternate coolant passage designs and in the evaluation of the flowpressure drop characteristic of the ATS turbine bucket cooling system.

\section{Section 2.2.3.5 (GTETIH) Surface Enhanced Internal Heat Transfer}

\section{Section 2.2.3.5.1 (GTETS2NHT) Trailing Edge Flow Test - S2N}

\section{Objective}

The objective of this task is to perform heat transfer tests in the trailing edge region of the second-stage nozzle using a Plexiglas ${ }^{\mathrm{TM}}$ model built in 1995. The purpose of the work is to generate a cooling scheme that will (1) even out the coolant side heat transfer coefficients along the channel and (2) yield results that are comparable to or better than the turbulent pipe flow correlation predictions.

The model keeps the important geometric variables of the passage close to the actual design. It has thin-foil heaters on both the suction and pressure sides, and liquid crystals to determine the temperature distributions. Tests were planned to investigate the triangular passage performance with several turbulator designs.

\section{Plans for Next Quarter}

This task has been completed.

\section{Technology Application}

The test results for cooling passages in the second-stage nozzle trailing edge cooling circuit provided the necessary design information and turbulator configurations for the ATS secondstage nozzle. This allows the design to obtain the desired heat transfer enhancement for the passages and to channel the cooling flow near the apex of the triangular flow passage near the trailing edge region effectively.

\section{Section 2.2.3.5.2 (GTETIH) Trailing Edge Heat Transfer Tests - S2B}

\section{Objective}

The task objective is to provide adequate experimental data to verify the performance of the second-stage bucket trailing edge cooling circuit.

Because film cooling and trailing edge bleed cooling are incompatible with the ATS gas turbine objective of closed circuit cooling, the bucket trailing edge must be cooled completely by convection in the trailing edge cavity. The geometry and flow conditions in the trailing edge cavity are different from any analyzed and tested previously. The heat transfer 
coefficients in the cavity are determined experimentally using a scale model. The experimental results are used to guide and improve the design of the bucket.

\section{Progress for this Quarter}

The computational fluid dynamics (CFD) part of this task was completed. The CFD results were summarized and documented in an informal report to the GEPS technical leader.

Three sets of tests were performed using the liquid crystal heat transfer measurement technique. All were aimed at determining the effect of the turn guide vane on bucket tip heat transfer.

The data from all three sets of tests were reduced to a useful form and were presented in previous reports. The heat transfer coefficients were calculated using $T_{\text {bulk local }}$ as described in previous reports. These results were scaled to the actual ATS gas turbine conditions using the techniques and assumptions described previously.

\section{Plans for Next Quarter}

The model is showing signs of wear, particularly the heaters and liquid crystals. It will be refurbished during $2 \mathrm{Q} 97$. The most recent test will then be repeated to ensure repeatability of the data and to characterize the entire region of interest fully.

\section{Technology Application}

The results of the tests conducted as part of this task were used directly in the design of the second-stage bucket for the ATS gas turbine.

\section{Section 2.2.3.5.3 (GTETIH) Outer Band Liquid Crystal Heat Transfer Tests - S1N}

\section{Objective}

The objective of this task is to perform heat transfer tests with a representative outer band impingement configuration and measure the heat transfer coefficient distributions underneath the impingement jets. The data will be compared with the design calculations and expectations. A test rig is used to simulate the design impingement jet plate geometry as closely as possible. The test section walls are instrumented with three etched thin-foil heaters and a liquid crystal layer to measure the local wall temperature distributions as a function of flowrate and heat flux. The temperature data are then converted into heat transfer coefficient values.

\section{Plans for Next Quarter}

This task has been completed.

\section{Technology Application}

The test results obtained with the flow and heat transfer tests showed that the design calculations and models were able to successfully predict the flow directions and heat transfer coefficients for the complicated impingement pattern of the ATS first-stage nozzle outer band. The tests also showed that the heat transfer is dependent on the leading and trailing edge cavity discharge pressure levels. The data also showed that an impingement design without a 
separating rib is more effective than a design with a separating rib on the suction and pressure sides.

\section{Section 2.2.3.5.4 (GTETIH) Convex Cavity Heat Transfer Tests - S1N}

\section{Objective}

The objective of this task is to perform flow and heat transfer tests in a simple test rig representative of a first-stage nozzle convectively cooled passage geometry with two different turbulator designs to determine the effect of corner radius on the heat transfer enhancements obtained with the turbulators. Two simplified plastic models of the cooling channel were constructed with the important geometric variables kept as close-as possible to the actual design. An additional test section was also constructed to model the exact geometry of the convectively cooled cavity, which incorporated the area changes along the radial distance. The inside surfaces of the test pieces were coated with liquid crystal paint or a liquid crystal sheet, and transient and steady-state tests were run to determine the friction factors and local heat transfer coefficient distributions. The results were also compared with the CRD database. An additional flow test was conducted with a metallic test section manufactured with exactly the same dimensions as the prototypical passage to verify the flow models of the design.

\section{Plans for Next Quarter}

This task has been completed.

\section{Technology Application}

The results of these tests with rectangular and filleted turbulated tubes provided the designer with information on the differences between the two and showed that the database can be used to predict the friction and heat transfer. The results with various turbulator heights changed the design requirements to prevent large variations in the local heat transfer coefficients. The test data also showed that the heat transfer enhancements are not reduced at the high Reynolds numbers of interest for the present design.

\section{Section 2.2.3.5.5 (GTETIH) Bucket Tip Closed Circuit Cooling}

\section{Objective}

The objective of this task is to measure non-rotating heat transfer and pressure drop in the $180^{\circ}$ tip turn region of a two-pass serpentine bucket tip, and to evaluate the ability of an enhanced surface in the tip region to enhance the tip cooling without a substantial pressure drop penalty.

\section{Plans for Next Quarter}

This task has been completed.

\section{Technology Application}

These results were used by the designers of the ATS gas turbine buckets to design the tip turn regions of serpentine cooling circuits. 
Section 2.2.3.5.6 (GTETLE) Bucket Leading Edge Heat Transfer Testing

\section{Objective}

The objective of this task is to evaluate turbulator geometries for the first-stage bucket leading edge passage by performing non-rotating heat transfer and pressure drop tests at high Reynolds numbers on scaled models of the leading edge passage.

\section{Plans for Next Quarter}

This task has been completed.

\section{Technology Application}

The heat transfer and pressure drop results from this task were used in the design of the firststage bucket in the ATS gas turbine.

\section{Section 2.2.3.5.7 (GTETIH) Surface Enhanced Internal Heat Transfer - S1N}

\section{Objective}

The objective of this task is to investigate and determine the heat transfer coefficient enhancements that could be generated under impingement jet cooling modules by adding surface roughness elements without increasing the total system pressure drop. The effect of bumps missing in some regions due to manufacturing problems will also be investigated.

The test section used for impingement heat transfer tests is enclosed in a high-pressure enclosure that can be operated at pressures up to 10.2 atm (150 psia) by means of a backpressure control valve. The impingement air is fed to a supply chamber equipped with a square impingement jet plate that can accommodate several hole configurations. The impingement test surface is in intimate contact with a copper block that is heated by four cartridge heaters. The impingement test plates, positioned at a controlled distance from the impingement jet plates, are instrumented with four embedded thermocouples that measure the plate temperature. Tests are conducted at various jet Reynolds numbers and several jet plate geometries. To investigate the effect of bumps missing in some regions, the high-pressure containment is modified so that a window can be attached at one end. A thin-foil heater and a liquid crystal assembly are glued onto the impingement test plate and the color changes observed with the liquid crystal video thermography (LCVT) system.

\section{Plans for Next Quarter}

This task has been completed.

\section{Technology Application}

The ANSYS analysis results provide the increases in wall temperature expected for various numbers of bumps missing. The acceptable temperature rise will determine the quality control criteria and the nondestructive testing technique for the missing bump number determination. The transient technique provides a nondestructive technique to check the non-uniformity of the cooling and the number of missing bumps. 


\section{Section 2.2.3.5.8 (GTETIH) Trailing Edge Heat Transfer Tests - S1N}

\section{Objective}

The first-stage nozzle trailing edge triangular cavity is air cooled and uses a combination of several cooling techniques. The turbulated main passage feeds several trailing edge slots whose heat transfer is enhanced by pin fins and high-solidity turbulators. The root region includes a $180^{\circ}$ turn that feeds three trailing edge cooling slots. The flow and heat transfer inputs for the design are complex and need verification testing.

The objective of the task is to build a representative model of the trailing edge cavity and measure the local heat transfer coefficients to ensure that (1) the heat transfer coefficient correlations used in the design are appropriate and (2) there are no flow recirculation or uneven distribution regions where the heat transfer coefficients are lower than the expected values.

\section{Progress for this Quarter}

A conceptual design of the test section was prepared based on cross sections provided by the GEPS design staff. The model divides the cavity into several regions and matches the wetted perimeters and flow areas as closely as possible. These discrete cross sections are then connected with a linear variation of the passage geometries. The conceptual design, including the altered cross sections, was released to the CRD machine shop. A tool paths program for a numerically controlled machine was prepared by the machine shop and an acrylic model of the test section was manufactured. Measurements will be taken to compare the manufactured part with the model dimensions.

Acrylic model measurements were made to compare the manufactured part with the model dimensions, and the manufactured part was found to be within acceptable tolerances. The separating rib walls and turbulators are being manufactured from balsa wood and acrylic plastics.

One wall of the acrylic model was covered with a liquid crystal sheet and a thin-foil heater. The flow separation ribs, the pin fins, and the balsa wood turbulators were attached to the opposite wall with a clearance that will allow for a gasket between the two faces. A number of static pressure taps were also drilled along the cooling passage to measure the flow characteristics.

\section{Plans for Next Quarter}

An inlet transition piece and a wall at the $180^{\circ}$ turn are needed before the heat transfer tests can be started. These items will be fabricated and installed. Liquid crystals with thin-foil heaters will then be used to measure heat transfer coefficients.

\section{Technology Application}

The flow and heat transfer results obtained will verify the design tool predictions and ensure that the predictions are correct and that there are no regions that have friction and heat transfer coefficient values different from the design assumptions. 
Section 2.2.3.5.9 (GTETBKHT) High Reynolds Number Turbulator Static Heat Transfer Test

\section{Objective}

The objective of this task is to investigate and determine the heat transfer coefficient enhancements possible in the first-stage nozzle. Internal cooling will be supplied by two different types of convection: one using impingement heat transfer within the internal airfoil cavities, the other using high Reynolds number turbulated heat transfer within the aftmost convective channel of the airfoil. This task will concentrate on the latter type of heat transfer. Experimental work reported in the open literature on turbulator heat transfer enhancement and friction factors is limited to passage Reynolds numbers below 80,000. This task will supply data and correlations to be used for advanced machine design conditions. Heat transfer and pressure drop data are required at far higher Reynolds numbers than previously tested with common turbulator geometries and passage aspect ratios.

\section{Plans for Next Quarter}

This task has been completed.

\section{Technology Application}

The results from this task are applicable to any non-rotating components in the ATS gas turbine that use turbulated passages for cooling. As long as rotational effects are accounted for, these results are also applicable to turbulated passage cooling of rotating components.

\section{Section 2.2.3.5.10 (GTET) Impingement Degradation Effects}

\section{Objective}

The internal nozzle design verification tests conducted in 1996 with various impingement jet plates and test plates showed that the impingement heat transfer coefficients measured under the first and second rows of the impingement jets were lower than the open literature correlation predictions (Metzger). Although this difference was not significant in some regions, it was important in others where accurate knowledge of the heat transfer coefficients under the first two impingement jets is important. The differences between the design verification test results and the correlation predictions were attributed to the fact that in those tests the first row of jets was near a wall with zero velocity boundary conditions while in the correlation tests the first row was adjacent to a constant pressure boundary condition.

The objective of this task is to understand the physical phenomenon that causes the observed difference. The local static pressure distributions along the cross flow regions of the impinging jets will be measured for two inlet boundary conditions, one with a wall and the other with a constant pressure. Tests will also be conducted with the cross flow discharging in one direction across the impingement jets and discharging in two directions symmetrically from the center row.

\section{Progress for this Quarter}

There was no activity on this task in 1Q97. 


\section{Plans for Next Quarter}

Static pressure taps will be drilled along the rib walls of the impingement jets along the cross flow direction. The static pressure distributions will be measured and correlated with the upstream boundary conditions of the first impingement jets. The test section will be modified to accommodate the various boundary conditions of interest as well as the cross flow discharging in one direction or discharging symmetrically in two directions.

\section{Technology Application}

The results obtained will clarify the discrepancy between prior test results and those from open literature correlation predictions (Metzger). The new data will improve the design of the first-stage nozzle internal cooling scheme.

\section{Section 2.2.3.5.11 (GTETIH) Production Airfoil Flow Checks}

\section{Objective}

The cooling flow circuits of the first- and second-stage nozzles and buckets of the ATS gas turbine have complicated flow configurations. Design flow models involve several empirical friction factors and flow element head loss coefficients that were taken from the best knowledge available. The models need experimental verification with the typical cast components.

The objective of the flow checks, conducted with air, is to check the flowrates and static pressure distributions of two typical cast first- and second-stage nozzle and bucket components. The results will be compared with the design flow model predictions. The measured overall coolant flowrates for a given overall inlet-to-exit pressure ratio will also form the basis for future quality flow tests to be conducted at GEPS to ensure that every component fulfills the flow design requirements.

\section{Progress for this Quarter}

As preliminary tests, two first-stage nozzles used for the GEAE Cascade LCF tests were flowtested in February. The two nozzles are similar to the ones that were flow-tested in November 1995 and were used for the GEAE Cascade heat transfer tests. The nozzles have steam circuits and two air-cooled cavities near the trailing edge. The flow test data were compared with the flow models and the 1995 test results.

The full-scale First-Stage Nozzle Test setup in Evendale, used for heat transfer and LCF tests, has two fully instrumented airfoils that are air and steam cooled. Two water-cooled copper airfoils constitute the side walls of the test facility. These water-cooled airfoils form the pressure and suction side walls of the cascade facility. During March the water cooling circuitry was flow-tested to generate flowrate vs. pressure drop data and compare them with data obtained from the original design.

\section{Plans for Next Quarter}

The necessary flow tests and static pressure distribution measurements will be performed as the cast nozzle and bucket components are available from the manufacturer. 


\section{Technology Application}

The flow and static pressure distributions results obtained with the cast components will verify the design flow model predictions and ensure that the predictions are correct and that there are no regions that have friction and head loss factors different from the design assumptions.

\section{Section 2.2.3.6 (GTETEH) Surface Roughness Effects on Heat Transfer}

\section{Objective}

The effects of TBC surface roughness on external heat transfer will be characterized using flat plates tested in an atmospheric wind tunnel. An advantage of flat plates over airfoils is that TBCs can be applied easily and polished to uniform thickness and surface finish. Full mapping of the TBC surface topography will be performed. Reynolds numbers will span those expected in the ATS turbine inlet nozzle surface away from the leading edge. Verification tests on airfoil replicas will be performed.

\section{Progress for this Quarter}

All test rig drawings were completed and submitted to the CRD machine shop. Work to fabricate the central test plates began. Instrumentation for the first six plates was ordered.

\section{Plans for Next Period}

Test section fabrication will be completed and the test facility assembled for initial pressure checkout. The test plates will be sent to the vendor for instrumentation.

\section{Technology Application}

The results will help determine what surface finish is allowable for the airfoil TBCs.

\section{Section 2.2.3.6.1 (GTETEH) Heat Transfer for Production Aero with TBC Spall Effects - S1N}

\section{Objective}

The objective of this task is the quantification of the external heat transfer coefficient distribution for the production aerodynamic design definition of the ATS turbine inlet nozzle airfoil.

A previous task begun in Phase 2 and completed under Phase 3 quantified the external heat transfer distributions for the original aerodynamic design, including effects due to roughness and turbulence intensity. The production aerodynamic design is sufficiently different in crucial regions to warrant a new series of tests, again including roughness and turbulence intensity effects. The new aerodynamic definition for the nozże is specifically designed to lower the heat load on the airfoil. Results from the previous cascade tests are being used on the new airfoil design, but with the assumed validity of local Reynolds number scaling of heat transfer coefficients. Since such scaling of results has no experimental basis for airfoils that deal with complex flows, it is necessary to verify the new design. Results from the original series of tests will be used to reduce the present task efforts to a minimum. Most of the original apparatus hardware from the ATS Turbine Inlet Nozzle Cascade will be reused for this task. 


\section{Plans for the Next Quarter}

This task has been completed.

\section{Technology Application}

The results from this series of tests yielded external heat transfer load validation on the production first-stage nozzle design.

\section{Section 2.2.3.6.2 (GTETEH) Surface Roughness Effects on Heat Transfer}

\section{Objective}

The external heat loading for the ATS first-stage nozzle airfoil is heavily dependent upon the nonlinear effects of surface roughness, especially as the nozzle design cannot rely upon film cooling. Given the current state of turbine cooling technology, the only viable method for determining the nozzle heat load with roughness effects is experimental validation of the heat transfer distribution under non-dimensional engine-representative conditions.

The ATS Turbine Inlet Nozzle Cascade has been used to provide data on external heat transfer coefficients on airfoils with surface roughness. The cascade incorporates instrumented airfoils with flow conditions representative of the ATS inlet nozzle geometry. The appropriate non-dimensional parameters for dynamic similarity are close to those of the engine inlet nozzle. External heat transfer coefficient distributions are measured through the use of embedded thermocouples, with a constant surface heat flux condition supplied by thin-foil heaters. Surface roughness elements of the appropriate size and distribution were bonded onto the surface heaters. Data include various roughness levels, distributions, and types to allow the calibration of predictive methods. Characterization of surface roughness effects includes the interactive nature of roughness with fluid dynamic conditions such as acceleration. The cascade has also been used to assess the effects of transition piece wake shedding on airfoil heat transfer, the effect of extreme surface roughness representative of as-sprayed thermal barrier coatings, and the effect of modeled coating spallation on heat transfer enhancements.

\section{Plans for Next Quarter}

This task has been completed for the current cascade airfoil configuration.

\section{Technology Application}

The test results were used directly in the design of the ATS first-stage nozzle airfoil. Thus the cascade conditions for an appropriate rough surface condition, with elevated freestream turbulence intensity from a DLN combustor mockup, were used as the convective heat load definition for the nozzle airfoil. Since modeled spallation heat transfer enhancements were equal to or below the assumed enhancement levels for the nozzle design, the conservative nature of this portion of the design was verified. Cascade testing verified the requirement to polish the thermal barrier coating on the Full Scale Nozzle Cascade instrumented airfoils, thereby avoiding potential test problems in that task. The optimal relative location for the transition piece endwall segments, as determined through cascade testing, was incorporated into the turbine design. 


\section{Section 2.2.3.7 (GTETCP) LCF Coupon Tests}

\section{Section 2.2.3.7.1 (GTETCP) LCF and Crack Propagation Rate Tests}

\section{Objective}

The E-beam high thermal gradient test facility will be used to test several nickel-based superalloy (N5) coupons for low cycle fatigue (LCF) durability. The coupons will be geometrically representative of a section of the turbine inlet nozzle airfoil containing hot and cold sides. Coupons will be instrumented for the evaluation of thermal conditions during testing. Tests will be performed to evaluate metal durability under conditions of temperature, thermal gradient, and stress representative of the ATS turbine inlet nozzle. Testing will be cyclic, developing cycles of exposure on the test coupons considered representative of engine cycles. Post-test evaluations of the TBC and metal conditions will be performed. Data will provide a basis for LCF life evaluations.

In addition to the high thermal gradient testing of superalloy coupons for LCF durability, this task will also assess the crack propagation rate of N5 in the presence of steam. This will be done in two ways: (1) isothermal, mechanically loaded testing of tubular specimens through which steam is passed and (2) high thermal gradient testing of a tophat specimen in the presence of steam. Post-test evaluations of the metal conditions will be performed. Data will provide a basis for LCF life

\section{Progress for this Quarter}

\section{LCF Testing}

An analysis was run to determine test conditions for a tophat fillet specimen. The analysis is a pre-test prediction of thermal boundary conditions required to match design temperature and stress levels in the fillet. Analysis of test conditions for the tophat fillet specimen indicates that a modification to the fillet test specimen design is required in order to match design temperature and stress levels in the fillet. A tophat fillet specimen was modified, as recommended, and is now ready for testing. The plan for the Pt-Al-coated fillet specimen was updated to include instrumentation. The fillet specimen was instrumented with thermocouples and is ready for low level testing to validate the analytical model.

Testing of LCF tophat specimens continued on the as-cast specimens with applied TBC. At the time of this report, LCF specimen $\# 6$ completed E-beam cyclic testing. No visual damage was observed in either the TBC or the substrate.

Superheated steam can now be supplied to the tophat test rig as coolant. All facility work to enable this upgrade is complete.

\section{Crack Propagation Rate}

There was no activity on this task in 1 Q97. 


\section{Plans for Next Reporting Period}

The Pt-Al-coated tophat fillet specimen will be tested at low temperature and stress levels to validate the pre-test analysis and impingement nozzle design parameters. A strain map for the tophat fillet specimen will be developed from the test results.

Pre-test analysis of the tubular specimen will be done to define the appropriate test conditions. Three tubular specimens, each with initiated thumbnail crack, will be tested: one to validate the test method for notched specimens, one to assess crack growth rate in the presence of superheated steam, and one to assess crack growth rate in the presence of air.

\section{Technology Application}

The results of the tests conducted as part of this task will be used as a basis for LCF life evaluation of the first-stage nozzle and first-stage bucket for the ATS gas turbine.

\section{Section 2.2.3.8 (GTETSP) Steam Particulate Deposition}

\section{Section 2.2.3.8.1 (GTETSP) Steam Particulate Deposition Rig Testing}

\section{Objective}

The objective of this task is to measure the rate and location of steam particulate deposition in bucket tip turns and in two heat transfer structures to be employed within the ATS gas turbine nozzles and buckets. The information is to be translated into a steam purity specification and full-filter specification for the ATS gas turbine.

The approach employed is to use gas turbine combined cycle (GTCC) steam flowing in series through a special filter specified for the ATS gas turbine, then through the tip turns in a specially constructed centrifugal deposition rig, and finally through two static specimens consisting of turbulated and impingement-cooled specimens.

Amounts and locations of deposits in these specimens will be used to verify the predicted time-between-outages results from ATS Phase 2 studies.

\section{Progress for this Quarter}

\section{Static Specimen Exposure}

The static specimens, impingement and turbulated, installed in 1996 have been online for 31 and 38 weeks, respectively, with few outages. The specimens were taken off-line and examined with a borescope for foreign particle deposition. No deposit was visible, attesting to the cleanliness of the original steam and the effectiveness of the full-flow steam filter. The specimens were again taken off-line at the end of $1 Q 97$, when the steam system to which they were connected was shut down for a 7-year overhaul. The specimens will be examined with a borescope again in $2 \mathrm{Q} 97$ to determine whether any deposits formed.

\section{Steam Filter}

The steam filter went back on-line with the static specimens and has been on-line upstream of the specimens ever since. No increases in pressure drop across the filter were observed. 


\section{Centrifugal Deposition Rig}

The centrifuge was tested twice in 1Q97 with a new set of shaft seals. While steam leakage was reduced to within practical levels by going to smaller diameter, non-contacting seals, large power dissipation with the last seal set under a wide range of pressure and flow conditions would not allow a practical speed to be achieved reliably.

Starting in 2Q97, the centrifuge will be used as a test bed for a new steam seal that was proposed to increase efficiency.

\section{GT Cooling Steam Specification}

The earlier generated steam particulate specifications were expanded and integrated with chemical specifications for an overall steam purity specification for the gas turbine. Recommendations for conducting simplified, custom steam particulate measurements as part of the prototype operation were included in the specification.

\section{Steam Filter System}

CRD staff collaborated with the ATS filter system designers and joined in meetings with vendors developing the filter system, including a design review. Provision for filter performance and status monitoring, as well as ease of access to the filters for inspection and maintenance, was obtained with the designs.

\section{Plans for Next Quarter}

The static flow specimens (bucket and nozzle) will be examined for deposits and a decision will be made, based on cleanliness, as to the need for steam centrifuge specimen exposure. If large static deposits are found, the centrifugal exposures will be continued. In the meantime, the centrifuge will be disassembled and prepared for a leakage test of new ATS gas turbine steam seals as part of the CRD Steam Gland Brush Seals task reported on in Section 2.2.4.14.2. In addition, experience gained on the ATS steam deposition program will be transitioned by contributing to task force technology discussions involving (1) steam cooling system reliability and (2) specification of instrumentation required for reliable operation and diagnosis of the prototype ATS power plant

\section{Brush Seal Development}

Use of the centrifuge facility to test new seal designs is now being planned for a $2 \mathrm{Q} 97$ seal installation. Steam task staff worked with the seal staff to specify equipment for the seal test. The new seals will leak more than the current non-contact seals on the centrifuge, but the test will be short and is required to validate predicted leakage rates.

\section{Technology Application}

Data from tests under this steam particulate deposition task will allow for the necessary steam filter specifications to be established. The proper particulate filtering of steam, used for bucket and nozzle cooling is critical to the reliable long-term operation of the ATS gas turbine. 


\section{Section 2.2.4 (GTMT) Materials Technologies}

\section{Section 2.2.4.1 (GTMTSE) Steam Effects on Mechanical Properties}

\section{Objective}

The objective of this task is to evaluate the candidate turbine materials for any effects due to operation in a steam environment. Tests of materials that are exposed to steam will be performed to measure fatigue crack propagation, low cycle fatigue (LCF), and creep. Additional tests deemed necessary to meet design criteria will be performed. Comparisons will be made to data collected in air. Where necessary, the program will evaluate the roles of alternate heat treatments and/or surface treatments.

\section{Progress for this Quarter}

Notched and smooth bar LCF curves for the turbine wheel material were issued. Static and dynamic crack growth testing continued at one temperature. Baseline testing of the first piece qualification (FPQ) material in air continued. Threshold testing continued for specimens taken from the FPQ material. The tested specimens were evaluated with transmission electron microscopy (TEM) and image analysis techniques. Creep specimens from FPQ material were tested.

Machining of test specimens for evaluation in steam was initiated for three hot gas path materials. Specimens were produced for LCF, fatigue crack growth (FCGR), and creep.

Evaluations of welded and brazed joints in steam were put on hold because of test rig constraints. Additional specimens were prepared for test.

\section{Plans for Next Quarter}

Steam dynamic crack growth rate threshold tests, fatigue crack propagation tests, and creep tests of FPQ wheel material will continue. There will be continuing efforts to determine the effects of processing (such as forging flow direction and temperature distribution) on timedependent crack growth behavior of wheel material. LCF, FCGR, and creep tests for the various hot gas path materials will be initiated. Testing of steam delivery system joints in steam will be initiated.

\section{Technology Application}

This task will evaluate the behavior of turbine materials in a steam environment in order to account for the introduction of steam cooling.

\section{Section 2.2.4.2 (GTMTSO) Oxidation Due to Steam}

\section{Objective}

Testing of ATS materials in steam will be performed to evaluate the long-term oxidation responses to this environment. Specimens will be subjected to steam exposure in an autoclave and removed at specified intervals for examination of oxidation characteristics. 


\section{Plans for Next Quarter}

Because of the difficulties involved in static testing, this effort was terminated.

\section{Technology Application}

This task will evaluate the static behavior of turbine materials in a steam environment in order to account for the introduction of steam cooling.

\section{Section 2.2.4.3 (GTMTCE) Corrosion Rate Evaluations of Airfoil Overlay Coatings Objective}

The objective of this task is to evaluate the performance of ATS materials in potentially corrosive environments with various overlay coatings and substrate materials. Initial evaluations will be performed in small burner rigs with known contaminants. This will allow ranking of the corrosion rates of materials and coatings. Subsequent testing will be performed in facilities that better simulate gas turbine service conditions, including high gradients, for confirmation of burner rig results.

\section{Progress for this Quarter}

Approximately 2000 additional hours of exposure time were accumulated on those coated samples running in the high temperature oxidation rigs. High-temperature oxidation behavior of various overaluminided MCrAlY coatings and vapor phase aluminide coatings for both external and internal use are being compared against performance of the current coating systems. This information will provide the largest input to the selection of the next generation metallic coating system.

Alternate coating candidates will also be subjected to strain-to-crack tests in which the strain tolerance as a function of temperature is evaluated. This information will help rank the coatings in terms of their susceptibility to "craze" cracking during service. Initial testing on the standard coating was performed in 1Q97 and will provide the baseline against which the alternate coating systems will be compared. Several groups of specimens with modified overaluminide coatings were prepared for this test during the quarter.

\section{Plans for Next Quarter}

Strain-to-crack testing will be performed on the five groups of overaluminided test specimens currently available. Three additional groups are also being prepared and may be ready for test in 2 Q97 also.

\section{Technology Application}

This task will evaluate potential airfoil coatings in environments that reflect planned ATS turbine operating conditions. 


\section{Section 2.2.4.4 (GTMTBV) Compressor Blades and Vanes Materials and Processes}

\section{Objective}

Although material selections have been completed, this task will examine potentially less expensive materials for use in blades and vanes in the latter stages of the ATS compressor. These evaluations of alternate materials will be based on results of tests of mechanical properties, with emphasis on high cycle fatigue (HCF) properties. For the materials that have been selected, tests of critical properties will be conducted under ATS-specific conditions. Component tests of select parts will be conducted for life verification purposes and establishment of final manufacturing parameters.

\section{Plans for Next Quarter}

This task has been completed.

\section{Technology Application}

This task characterized the mechanical behavior of existing and new blade/vane materials in more aggressive environments than past compressor operation.

\section{Section 2.2.4.5 (GTMTVG) Compressor Variable Guide Vane System Design Support and Process Development}

\section{Objective}

Information to support selection of materials for the variable guide vane (VGV) bushings and thrust washers will be gathered to ensure a robust and reliable design. Testing will be conducted to confirm materials selections, cover any parameters outside of existing data, and gather data for new materials.

\section{Progress for this Quarter}

The candidate bushing and washer materials completed the impact tests. The oscillating wear tests continued.

\section{Plans for Next Quarter}

The impact tests will be analyzed and reported to Design Engineering. The oscillating wear tests should be completed in the next reporting period.

\section{Technology Application}

This task will provide operational test data on ancillary materials used in the VGV system. Potential bushing and sleeve materials will be screened.

\section{Section 2.2.4.6 (GTMTCS) Compressor Structural Materials and Processes \\ Objective}

Mechanical and physical property tests will be performed on ATS compressor structural materials to provide an expanded mechanical and physical property database for design 
validation and enhancement. Material processing parameters for prototype manufacturing of the components will be selected based on design requirements and discussions with vendors. When necessary, material and processing specifications will be modified or new ones written.

\section{Progress for this Quarter}

Tensile and high cycle fatigue (HCF) testing results for both wheel materials were reported to Design Engineering. GE continued technical support of the supplier as prototype diffuser castings were made. Nondestructive examination results were reviewed and corrective actions were defined to address several non-conformances.

\section{Plans for Next Quarter}

GE personnel will assist in the refinement of heat treat cycles and weld procedures at the diffuser supplier. The intention is to close out the first piece qualification (FPQ) review.

\section{Technology Application}

This task will continue characterization of compressor structural materials in test conditions that reflect service environments.

\section{Section 2.2.4.7 (GTMTRF) Turbine Rotor Forging Materials and Processes}

\section{Objective}

Processing parameters of forged large turbine rotor components will be optimized to achieve the desired forging attributes. These parameters include chemistry and processing temperatures as well as post-processing surface treatments. Sub-size and full-size forgings will be produced to verify and evaluate the processing approaches, and forging supplier process plans will be developed for all components. Forging acoustic properties will be determined by ultrasonic testing on test block and prototype parts. The attenuation, anisotropy, frequency bypass, and signal-to-noise ratio will be measured and used in fracture mechanics analyses to support rotor design. Optimized inspection methods, any necessary software, and scan plans will be developed based on the work with prototype parts. Property evaluations will be conducted to ensure that material behavior models used for design accurately reflect those achieved in parts made by the manufacturing process selected.

\section{Progress for this Quarter}

All rotor forgings were forge processed and heat treated. Mechanical properties were obtained from rim ring and near core sections by the forging vendor. Laboratory heat treatment studies are in progress to study the effect of solution temperature on mechanical properties.

Low cycle fatigue (LCF) tests continue at various temperatures and hold times. Nine creep tests and eleven notched rupture tests were completed. This completed the planned scope of the notched rupture test program. New tensile curves were issued to Design Engineering. Crack growth rate tests were continued. Static and dynamic crack growth rate tests continued. 


\section{Plans for Next Quarter}

The rotor forgings will be evaluated by GE for internal soundness and will be machined. Additional heat treatment results, at different solution temperatures, will be evaluated.

Crack growth rate and creep tests will continue. Smooth bar LCF hold time testing will continue. Static and dynamic crack growth rate tests will continue. Additional design curves will be issued as data become available.

\section{Technology Application}

This task will enhance process capabilities for manufacture of turbine rotor forgings.

\section{Section 2.2.4.8 (GTMTRS) Turbine Rotor Spoolies and Transfer Devices Materials and Processes}

\section{Objective}

Although material selections for the cooling system delivery systems have been completed, this task will perform testing to verify properties and identify potentially better materials. Any applicable or needed coatings or joint materials will also be identified. Procedures for joining delivery components together and inspecting them will be evaluated.

\section{Progress for this Quarter}

The initial round of tests on 80-mil sheets of steam delivery tubing material was completed. This included tensile, low cycle fatigue (LCF), and creep tests. A more extensive effort involving a larger matrix was started to meet the needs of Design Engineering. This matrix included 50-mil sheets in welded and parent metal forms. Two non-standard tests were identified for the tube specimens. One of them, the longitudinal tensile test, was completed. The other, the transverse tensile test, is in progress. Samples for spoolies that range from 6 to 20 mils were also obtained from the supplier.

Two processes were identified to enhance the LCF life of the tubes: shot peening and expansion. Tube samples were expanded to two trial dimensions; two peening conditions were also tried. All the resulting samples are being studied for residual stresses.

Two other nickel-based materials were identified as the alternate candidates for the steam delivery system. Three different heat treatments were identified. All the heat treatments were completed. The first phase of the screening process is tensile testing. Machining of the specimens is complete and testing is in progress.

Sample steam delivery tubing material, in the form of strips and welded tubes, and spoolies were received from vendors and machined into test specimens. Some of the samples were evaluated via microstructure examination and mechanical property testing. Discussions were held with spoolie and tube suppliers on the manufacturing processes used to fabricate these components.

The wear rig was assembled to complete block-on-shoe wear testing of spoolie coatings. Shakedown testing of the rig was completed. Test run \#1, a baseline test in ambient atmosphere on bare substrates, verified the accuracy of the test, giving values of coefficients 
of friction in agreement with those reported in the literature. Test run $\# 4$ was the first test run on one of the candidate coatings.

\section{Plans for Next Quarter}

The plate samples will be tested for the required properties (tensile, creep, LCF, HCF, and FCGR). Cast material, which is being considered for the radial-to-axial tube elbows and also for the stationary manifold, will also be tested. The residual stress study will be followed by an effort to quantify the benefit in terms of life.

After the first phase of screening, selected materials will be tested via slow strain rate tensile tests in steam. After that phase, a unique material will be identified as the alternate material. A full test matrix will then be launched on that material.

Wear testing of the candidate coatings will be completed and a few coatings will be selected. The selected coatings will be tested for fretting resistance. Test results will be used for final selection of a wear coating for the steam delivery system.

\section{Technology Application}

This task will develop processes and mechanical property data to optimize steam delivery hardware manufacture and subsequent operation.

\section{Section 2.2.4.9 (GTMTSB) Structural Bolting}

\section{Objective}

Mechanical and physical property tests on two high-strength bolting materials will be conducted at ATS turbine conditions. If required, manufacturing trials will be conducted to optimize forming processes.

\section{Progress for this Quarter}

The stress relaxation specimens continue to accumulate time in test. An enhanced scope test matrix was agreed upon with Design Engineering. Purchase of additional test material and subsequent machining of specimens was initiated.

\section{Plans for Next Quarter}

Future work will continue to be devoted to developing long-term relaxation data on the two prime bolting alloys.

\section{Technology Application}

This task will increase the database for flange/flange and wheel/wheel bolting applications.

\section{Section 2.2.4.10 (GTMTTA) Turbine Airfoils Materials and Processes}

\section{Objective}

Microstructure and mechanical properties will be evaluated for full-sized castings processed in this program. A comprehensive program will yield final specifications with appropriate heat 
treatments and will quantify the effects of ATS airfoil geometry and structure/property variability. Casting processes will be developed for all airfoils by employing developmental casting trials. Critical nozzle and bucket long-term material properties will be measured at elevated temperatures. Metallic coating systems will be developed for internal and external oxidation protection of the airfoils. Samples will be coated using various techniques for optimization studies and process verification.

\section{Progress for this Quarter}

Work was performed on casting defects, thinwall creep, transverse creep, and other materials properties for various bucket and nozzle alloys. Casting defects were tested at four selected temperatures to determine their effects, if any, on low cycle fatigue (LCF) life in the first-stage airfoil material. The defect types tested included low angle boundary, high angle boundary, freckle, and shrinkage. Thinwall creep testing was initiated on 30-mil sheet specimens of the first-stage airfoil material at four selected temperatures and various stresses. Test results from this effort will be combined with existing creep data from 60-mil, 100-mil, and 357-mil specimens to determine the effects, if any, of thin sections on creep life. Transverse creep testing was initiated in the second-stage bucket material at five selected temperatures to determine orientation effects. Third-stage nozzle material characterization tests were initiated to supplement existing data. Additional design curves were issued for various bucket and nozzle materials. Lifing methodology was established for airfoil welded and brazed joints.

\section{Plans for Next Quarter}

Additional LCF tests on defect-containing first-stage airfoil material will be conducted. LCF and other mechanical tests on third-stage nozzle material will be initiated. Long-term creep tests on various bucket and nozzle alloys will be continued. Weld and braze joint feature tests will be developed. A test matrix for standard specimen configuration testing will be completed. Materials for test will be procured and testing initiated.

\section{Technology Application}

This task will enhance the database of mechanical properties at service conditions for bucket, nozzle, and shroud materials.

\section{Section 2.2.4.11 (GTMTCB) Combustion Materials and Processes}

\section{Objective}

Properties of materials for combustion components will be evaluated at ATS conditions.

\section{Progress for this Quarter}

There was no activity on this task in $1 \mathrm{Q} 97$.

\section{Plans for Next Quarter}

Metallurgical and manufacturing evaluation of castings previously produced will be continued. 


\section{Technology Application}

This task will enhance processes and mechanical property data to optimize combustion hardware manufacture and subsequent operation.

\section{Section 2.2.4.12 (GTMTST) Turbine Structures Materials and Processes}

\section{Objective}

Producibility evaluations for the turbine structures will include selection of materials processing parameters and chemistry, and preparation of material and process specifications. Processing trials will be used to confirm producibility and verify capabilities of suppliers. Testing will be conducted where necessary to evaluate the materials under ATS conditions.

\section{Progress for this Quarter}

Steam manifold adapter casting requirements were reviewed with potential suppliers. Various process specifications were revised to include acceptance requirements for the ATS turbine components.

\section{Plans for Next Quarter}

Support of the suppliers' metallurgical activities will be continued as the various components are cast, fabricated, and/or machined.

\section{Technology Application}

This task will continue characterization of turbine structure materials in test conditions that reflect service environments.

\section{Section 2.2.4.13 (GTMTSH) Turbine Shells}

\section{Objective}

Materials and processes will be identified for production of the turbine shells. Specifications will be defined after material property testing and process verification/optimization trials are conducted to achieve the best quality part to meet all design criteria.

\section{Progress for this Quarter}

The inner shell process specification was revised to include acceptance requirements for the ATS turbine components."

\section{Plans for Next Quarter}

The supplier's manufacturing process plan and welding procedures for the inner shell will be reviewed.

\section{Technology Application}

This task will enhance characterization of turbine shell materials in test conditions that reflect service environments. 
Section 2.2.4.14 (GTMTSR) Seal Technology

\section{Objective}

Improved gas path seals will be developed for the ATS turbine utilizing seal technology developed for aircraft engine components where applicable. The technology will be evaluated using developmental hardware and samples.

\section{Plans for Next Quarter}

This task has been completed.

\section{Technology Application}

This task optimized seal attachment processes focused on airflow leakage restrictions to enhance performance.

\section{Section 2.2.4.14.1 (GTFFTSSESV) Hot Gas Path and Transition Piece Cloth Seals}

\section{Objective}

Seals between the hot gas path turbine components are required to help meet the ATS combined cycle efficiency target. The objective of this task is to develop and test cloth seals that meet both leakage performance and life requirements. Specifically, improved sealing performance that reduces the equivalent gap of the seal is sought by replacing the current Q-tip seals with a cloth sealing system. The cloth seals also need to meet the same full-life requirement.

Seals between the combustor transition piece and the first-stage nozzle are required to help meet the ATS combined cycle efficiency target. The objective of this task is to meet both leakage performance and life requirements. Specifically, advanced cloth seals will be developed for the transition-piece/first-stage-nozzle junction. Life consistent with the prescribed inspection interval is required.

\section{Progress for this Quarter}

\section{Hot Gas Path Cloth Seals}

A detailed work plan, including the identification of deliverables, was developed.

Seal geometries for all stages of the ATS gas turbine were completed. Jaw design for testing seal junctions was completed, and test seals for leakage performance at junctions were fabricated. The test plan was modified to evaluate seal junctions (sharp and rounded corners). Seal junction test jaws are being fabricated.

A detailed test plan for testing seal junctions is being developed.

\section{Transition Piece Cloth Seals}

A detailed work plan, including the identification of deliverables was developed.

The finite element analysis (FEA) of inner and outer seal designs was completed; interference checks for all relative thermal growth histories and tolerance stack-ups were reviewed. Recommendations were made for final "shelf" geometry at the first-stage nozzle where the 
seal comes in contact. These recommendations were arrived at after detailed FEAs were run for several relative position cases and ascertaining that there was no yielding. The first set of inner and outer transition piece seals is being fabricated.

A detailed test plan for high temperature low cycle fatigue (LCF) and material characterization was completed.

Plans for Next Quarter

Hot Gas Path Cloth Seals

Seal test data will be evaluated. Jaws will be fabricated for testing junctions

Transition Piece Cloth Seals

Tests for high-temperature low cycle fatigue (LCF) and material characterization will begin. These tests will be performed on $30.48-\mathrm{cm}$ (12-inch) samples cut down from actual seals destined for field tests. Side seals will be developed.

\section{Technology Application}

Cloth seal design concepts developed thus far are being designed as specific components for the ATS gas turbine. More tests are underway to determine design attributes that influence their application in practice: seal assembly, tolerances, and sensitivity to slot geometry.

\section{Section 2.2.4.14.2 (GTETBS) Steam Gland Brush Seals}

\section{Objective}

Brush seals will be developed to minimize steam leakage in the steam gland. Leakage reduction will increase the efficiency of the ATS gas turbine. The successful implementation of brush seals in the steam gland will also allow for a reduction in the axial length of the steam gland. The shorter length will result in a manufacturing cost reduction.

\section{Progress for this Quarter}

There are two seal locations to be considered: aft of the steam scroll is a leakage flow with a low-pressure drop; forward of the scroll is a leakage flow with a high-pressure drop. A singlestage brush seal design was developed for the first location and a two-stage brush seal for the second. Static leakage tests were used to determine the leakage performance under operating conditions. Computational fluid dynamics (CFD) modeling was used to design the geometry of the two-stage seal. Wear is assumed to occur mostly during transients, therefore, the wear life is being determined by testing under conditions based on extreme transient conditions. The design will be validated by sub-scale rotary tests under operating conditions.

The objective of the dynamic leakage test is to measure seal leakage during rotation and to determine the durability of the two-stage seal design in a high-pressure steam environment. A design review of the test hardware for the Ocean State Power steam deposition test rig was completed. A trip was made to the site at Ocean State Power to determine the piping changes necessary to accommodate the larger flow through the rig. The seal holder design was completed and released for manufacturing. 
The brush seal design was completed and orders for two sets of seals were placed with Cross Manufacturing for delivery in May 1997.

The objective of the sub-scale wear test is to determine the wear characteristics of the brush seal at machine operating conditions. The brush seal vendor completed a twenty-hour subscale wear test of the brush seal. The predicted transient conditions in the turbine exceed the capability of the test rig. The seal-to-shaft interference in the test rig was increased in order to partially compensate for the lower pressure difference across the seal. The larger interference increases the contact pressure between the bristles and shaft. Wear rate on the brush seal was low. No wear was observed on the $\mathrm{IN} 718$ rotor.

\section{Plans for Next Quarter}

The cost and cycle time for a new rotor for the steam deposition test rig will be investigated. A new rotor will eliminate concerns about the existing rotor such as surface condition, material differences compared to the ATS turbine shaft, and steam condensation at the rotor ends. Instrumentation for the test will be ordered and a detailed test plan prepared for the June 1997 test.

\section{Technology Application}

The brush seals will be used in the first machine by nesting the brush seal in the labyrinth seal packings. A slot will be machined in the labyrinth seal to accept the brush seal. On subsequent machines, the steam gland can be shortened to take advantage of improved sealing and reduce the manufacturing cost of the steam gland.

\section{Section 2.2.4.15 (GTMTAR) Airfoil Repair}

\section{Objective}

Existing techniques will be evaluated and adapted for the material/geometry combinations unique to the ATS turbine airfoils to extend component life.

\section{Progress for this Quarter}

Efforts continue to examine the repair of single crystal alloys.

\section{Plans for Next Quarter}

Studies will continue to evaluate repair methods for single crystal alloys.

\section{Technology Application}

The ability to repair single crystal airfoils will result in more cost-effective flow path components. 


\section{Section 2.2.5 (GTTT) Thermal Barrier Coating Technology}

\section{Section 2.2.5.1 (GTTTSD) Coating System Development}

\section{Objective}

Plasma spray TBC coating processes will be developed for specific ATS combustion and turbine components. Both axisymmetric and non-axisymmetric plasma gun and part motions will be developed. Coating evaluations will consist of metallography, property measurements, and thermal cycling exposure. Computer simulations, motion trials on part replicas, and spray trials on parts will be used for improving robot path planning accuracy. Improved process monitoring will be developed to increase process repeatability and control.

The TBC manufacturing technologies portion of the task will focus on integration and compatibility between TBC processing and other component manufacturing steps. Techniques to prepare components for spraying will be defined. Fixturing and masking will be developed. Surface finishing techniques will be developed.

The TBC process and diagnostics portion of the task will focus on achieving a better fundamental understanding of the TBC application process. Specific process conditions critical to the thickness and properties of the TBC system will be evaluated. Continuing work will focus on identifying critical-to-process characteristics (CTPs) for the ceramic top coat and metallic bond coat. The CTPs will be those directly controllable aspects of the coating process that most strongly influence process variability and TBC quality.

The TBC nondestructive evaluation (NDE) portion of the task will develop NDE techniques to measure attributes and properties of TBCs on turbine hardware that are relevant to manufacturing. The primary focus will be on development of methods to measure coating thickness.

\section{Progress for this Quarter}

The three FANUC Robotics M710i/RJ2 systems (two development systems located in Schenectady, NY; one production system located in Greenville, SC) are being fully evaluated to assure matched performance. Equivalency of non-robotic booth equipment is being similarly performed. The evaluations will be completed in $2 \mathrm{Q} 97$.

A Visible Laser System developed by CRD will be used during motion verification to adjust the robot program for optimal alignment to the part surface. The laser system design, development, and fabrication are complete. Precision laser targets were developed and tested for measuring velocities on airfoils. These targets are fabricated from soft aluminum, which allows for very good compliance to the part surface. Initial testing on production buckets has demonstrated excellent results.

A nozzle replica, fixture, and turntable platen were fabricated to support development of motion control and path programming techniques. This new replica system incorporates alignment pins throughout all stages to assure precise and repeatable test setups for all motion performance measurements. In addition, twelve stainless steel airfoil replica sections were fabricated for motion optimization trials. 
Two approaches for inverse time motion programming are being developed. The first is a FANUC Robotics product called Segment Time Programming (STP). STP motion development and programming techniques are initially focused on "Patch Motion" in support of the first set of ATS hardware. A set of progressive experiments was designed, beginning with constant velocity tests and leading to a series of variable velocity tests. Trials on both buckets and nozzles resulted in significant reductions in spatial coating thickness variation.

The second programming approach is a custom product being developed by CRD, called Coordination through Short Motion Programming (CSMP). CSMP testing accomplished both optimized path acceleration and robot/part motion synchronization using the nozzle replica. Testing in 1Q97 demonstrated significant improvements over developments achieved in 1996. A patent disclosure entitled "Motion Planning Method for Robotic Application of Spray Coatings to Complex Shaped Parts" is in preparation.

Testing and evaluation of protective bond coats on substrate materials to be used for first- and second-stage airfoils, shrouds, and transition pieces continued. Selection of bond coats for the first ATS hardware will take place in 2 Q97.

Two experimental matrices were run to identify process parameters for transition pieces. Measurements of powder particle temperature and velocity were taken using an in-flight particle sensor. Process conditions were adjusted to obtain different TBC microstructures; significant improvements in TBC properties (to nearly $5 \mathrm{X}$ ) over baseline production coatings were achieved. Thermal exposures were begun in order to evaluate aged TBC properties. Measurement of TBC strain tolerance following thermal exposure will be performed in the second quarter.

\section{TBC Manufacturing Technologies:}

A gun tooling system was developed to provide precise and repeatable gun mounting. A prototype tooling system was approved for fabrication and test.

Trial airfoils were provided to several vendors for evaluation of surface finishing capability. Tumbling trials were initiated using staged masking to reduce material removal at leading and trailing edges. Experiments to study the effects of TBC surface finish on airfoil heat transfer will be continued using flat plates for improved control of TBC surface finish and thermal resistance (Section 2.2.3.6). The data will be used to correct the TBC surface roughness measured using a cone stylus profilometer to the hydraulic TBC surface roughness.

\section{TBC Process and Diagnostics:}

Work in 1997 will focus on the TBC process technologies needed for production of the first ATS hardware. Subtasks addressing specific process issues are:

- Identification of process parameters to extend hardware and coating life using the baseline plasma gun.

- Evaluation of alternative plasma guns to reduce the risk of having only one gun vendor and to achieve longer gun hardware life.

- Evaluation of plasma mini-guns for coating welded joints between second-stage nozzle segments. 
- Evaluation of the effect of substrate preparation procedures on the life of the substrate and coating.

- Definition of the process for measuring the surface temperature of the TBC as it is being applied.

- Support of development of a gas-fired auxiliary heating source for controlling part temperature during coating.

- Preparation of a summary of air plasma spray (APS) bond coat work from 1996.

Information for various plasma guns was accumulated and suggested process conditions were requested from the gun vendors.

The feasibility of using a plasma mini-gun to coat the welded joint for second-stage nozzle doublets was evaluated. A model was generated to simulate the space restrictions for a plasma gun when the two nozzles are welded together. A search to find a gun small enough to coat the entire weld joint with enough power to achieve the required coating properties led to one prime candidate. Work with the nozzle model showed that this gun could easily pass through the nozzle cavity. However, initial work to determine the quality of the coating from this gun showed extremely poor deposition efficiency. Designed experiments were performed that significantly improved the deposition efficiency and led to acceptable microstructures for both the bond coat and TBC. Further experiments were performed to evaluate the potential for overheating the part if the gun motion had to be stopped on the part and reversed. Experiments showed that temperatures were well below those expected to degrade the mechanical properties of the substrate material.

Although most of the work with this mini-gun was favorable, there was significant downtime due to equipment problems. A newer gun will be provided to determine whether the age of the first gun degraded its reliability.

Preliminary evaluation of the gas-fired auxiliary heating source in the production spray cell showed significant improvement in part temperature control over plasma gun preheating alone. The system shows excellent potential for controlling part temperature in production with further planned modifications.

A preliminary summary of APS bond coat experiments was completed. Pareto diagrams were generated to show the relative importance of process variables to the coating characteristics. For all of the bond coat characteristics evaluated, deposition temperature had a large effect. Other process conditions alșo showed significant effects on bond coat characteristics.

TBC Nondestructive Evaluation

Two eddy current instruments were tested using the manual setup for measurement of TBC top coat thickness. Gauge repeatability and reproducibility studies were performed to evaluate the capability of these instruments for meeting ATS requirements. Only one instrument, a Nortec Model 24, was found to be acceptable when used with a flexible probe.

Development of an automated hybrid top coat thickness measurement system using a flexible eddy current probe in combination with a multi-axis scanner was begun. The various elements of the system were identified and purchased. These items include the computer, motion 
control software, redesigned probe and probe holder, and a modified version of the eddy current software being used in the manual eddy current tests.

A set of specimens is being evaluated for the effect of bond coat thickness on the eddy current readings. The tests are needed to determine the minimum bond coating thickness required to make the eddy current thickness readings accurate. Preliminary results show that the eddy current readings converge for different coating compositions and thicknesses as the testing frequency is increased.

Work was started on developing modifications of a fluorescent penetrant inspection technique in order to nondestructively evaluate the microstructure of the ceramic top coat.

\section{Plans for Next Period}

Robotic and non-robotic booth equivalency tests at three GE coating facilities will be completed. Testing of STP and CSMP for constant velocity control using the new nozzle replica and gun tooling will be completed. Testing of STP for variable velocity control will begin. Bond coats for the first ATS hardware will be selected. Process parameters for the transition piece using flat plates will be optimized. First spray trials on a development transition piece in the production spray cell will be conducted. Process conditions using the baseline and alternate plasma guns will be evaluated. Analysis to evaluate part temperature during coating will be completed. Installation of the first generation (Mark 1) automated eddy current scanner in the development and production facilities will be completed.

\section{Technology Application}

The process for applying APS TBC to ATS combustion and turbine components will be defined. This process will define the baseline upon which coating durability will be evaluated and evolutionary improvements will be made.

\section{Section 2.2.5.2 (GTTTRR) TBC Risk Reduction}

\section{Objective}

TBC durability will be evaluated under conditions very similar to the surface temperature, thermal gradient, and stress state of TBCs in ATS applications. An E-beam rig capable of inducing high thermal gradients will be used to assess the relative durability of various TBCs, and the controlling mechanisms of TBC failure will be characterized. TBCs with a spectrum of microstructures will be tested to determine the role of TBC thickness on stress development and failure mode in high thermal gradient conditions, the failure modes of various TBCs of different microstructures and deposition techniques, the role of number of cycles and hold times at high temperature on TBC failure mode, and the role of bond coat composition and roughness on TBC life and failure mode. The effects of environmental contaminants on TBC performance in high thermal gradient conditions will be investigated. Numerical modeling will be used to determine the stress, strain, and thermal gradient conditions in the various TBCs during the tests. 


\section{Progress for this Quarter}

No TBC testing occurred this quarter because of LCF testing commitments and installation of a steam cooling system in the E-beam thermal gradient test facility.

New calculations for the TBC fillet tophat showed a discrepancy between the TBC fillet and the ATS fillet conditions. The calculations showed that a slight modification of the tophat sidewalls and flange was needed to provide proper fillet stresses. A coated fillet tophat was machined to the new dimensions without TBC distress.

\section{Plans for Next Quarter}

A flat tophat pre-aged using long-hold furnace exposure will be tested for 2500 cycles at ATS conditions.

Testing of fillet tophats will begin. The first tests will be at low power "validation" conditions to compare the experimental results with the numerical predictions.

TBC top coat surface temperature measurements and bond coat temperature measurements will be performed.

\section{Technology Application}

Durability of the baseline TBC in an environment simulating that of the ATS baseline will be evaluated. These results will establish confidence that the TBC will provide acceptable minimum durability for safe and reliable operation of the ATS turbine within the time frame of the first inspection interval.

\section{Section 2.2.5.3 (GTTTDD) TBC Design Data and Life Analyses}

\section{Objective}

Thermomechanical failure modes in advanced TBCs will be identified, classified, and defined using empirical methods. Experiments will be performed to find key relationships among plasma spray processing variables, coating microstructure, coating physical and mechanical properties, and coating performance under simulated ATS conditions.

The relative contribution of oxidation and cyclic damage to the failure of two TBC systems will be evaluated in order to estimate the TBC life under the ATS gas turbine conditions. This will be accomplished by furnace cycle testing TBC systems using a series of dwell times per cycle $\left(0.1\right.$ to 20 hours/cycle) and dwell temperatures $\left(1037-1093^{\circ} \mathrm{C}, 1900-2000^{\circ} \mathrm{F}\right)$, and incorporating the results into an existing cumulative damage model. In support of this modeling approach, microstructural features of the bond coat and ceramic top coat will also be examined.

Numerical analyses will be performed to determine TBC stress states expected in ATS turbine components and in laboratory thermal cycling tests. The influence of the TBC stresses on TBC failure modes will be examined. Specially developed finite elements will be used for modeling the behavior of the interface cracks and free-edge stress singularities. The effects of bond coat roughness on TBC stress state, crack driving forces, and delamination failure will 
be examined. Parametric studies to determine the effects of bond coat and top coat properties on the TBC stress states will be performed.

The spatial and run-to-run variability of TBC thermal conductivity will be evaluated. Improved understanding of this variability is essential because the variation in TBC thermal conductivity can be several times greater than that seen in metals due to variations in TBC microstructure, leading to design inaccuracy. Various methods of measuring thermal diffusivity and conductivity on flat and curved samples will be evaluated. The gas pressure dependence of thermal conductivity as a function of temperature will be measured. The results will be used to estimate the thermal conductivity of TBC at ATS conditions.

Information from this task will be used as input to other tasks. Appropriate data and modeling results from parallel GE programs will be incorporated. Design guidelines will be developed for TBCs on ATS components. Ultimately, a TBC life analysis methodology and a life predictive model will be developed. These will include effects of long-term exposure on top coat and bond coat physical and mechanical properties.

\section{Progress for this Quarter}

Furnace Cycle Test

TBC evaluations using the furnace cycle test (FCT) continued. The FCT furnaces were calibrated using an improved procedure in order to reduce the site-to-site and furnace-tofurnace variability on measured TBC lives. Porous and DVC TBC specimens are being furnace cycled at $1093^{\circ} \mathrm{C}$ using dwell times of $0.1,0.75$, and 10 hours/cycle. Cycling at 20 hours/cycle will begin after the modified FCT procedure specification is approved by GEPS and transferred to MCL, Scotia.

Specimens were removed from each furnace after $5 \%$ and $25 \%$ of the estimated TBC lives. Tensile adhesion testing of these preliminary specimens indicated that the TBC life estimates in the original test schedule were reasonable and, in some cases, conservative. Based on these tensile adhesion results, the test schedules were not altered. Specimen failures are estimated to occur in 2 Q97.

\section{Thermal Conductivity}

The primary objective in 1997 is to produce refined design data for TBC thermal conductivity as functions of temperature and aging time. Air plasma spray (APS) TBC depositions were performed at identical conditions by CRD and GEPS manufacturing. The coatings were deposited on flat IN718 substrates that will be removed by chemical etch.

A proposal to perform measurements of the aged TBC samples was reviewed and approved by ORNL. A criterion for selection of aging times was developed based on a literature study. The following times were selected: 10, 100,1000, and 5000 hours. It should be noted that the longest time carries the experiment into 1998. Preliminary curves will be constructed based on exposures to 1000 hours.

The three furnaces necessary to carry out aging up to at least 1000 hours were identified and reserved. A thermocouple is being calibrated to profile the furnaces, and ramp-up and rampdown will be monitored to ensure minimum overshoot. A preliminary aging run to test sample positioning and possible warping is being prepared. 
A paper entitled "Effect of gas pressure on thermal conductivity of zirconia thermal barrier coatings" was submitted to the Surface and Coatings Technology journal.

\section{Plans for Next Period}

It is expected that furnace cycling at $1093^{\circ} \mathrm{C}$ will be completed for the dwell times of 0.1 , 0.75 , and 10 hours/cycle. Cycling at $1093^{\circ} \mathrm{C}$ using a dwell time of 20 hours/cycle and cycling at $1037^{\circ} \mathrm{C}$ using dwell times of $0.1,0.75$, and 10 hours/cycle will begin.

A thermocouple will be calibrated to profile the thermal conductivity aging furnaces. A preliminary aging run will be performed.

\section{Technology Application}

A database will be established that will link TBC properties and durability in laboratory tests to TBC durability in the ATS turbine. Ultimately this database will be used to predict TBC life as a function of temperature and strain at specific locations on ATS turbine components. The database will also be used to identify process improvements to the baseline TBC that result in improved properties and durability.

\section{Section 2.2.5.3.1 (GTFFTB) Bucket TBC Roughness and Spall Characterization}

\section{Objective}

This task will quantify the external airfoil heat transfer coefficients associated with the roughness characteristic of TBCs. This task places specific attention on the roughness associated with TBC structure, which can be very different from that of metallic surfaces or coatings.

Typical average roughness measurements made on surfaces cannot fully distinguish between metal finishes, artificial rough surfaces, and applied or polished TBC surfaces. While the measured average roughness values of such surfaces may be the same, the effect on external heat transfer may be quite different due to the specific character of the roughness. This task will use CRD's Transient Heat Transfer Cascade to test an airfoil coated with TBC that has been polished to various levels, and assess the effect of TBC-type roughness.

\section{Plans for Next Quarter}

This task has been completed.

\section{Technology Application}

The results from this task will be analyzed for consistency among the various roughness levels tested. The results will also be compared to other similar tests run in the same facility that used metallic rough surfaces. If the complete available data show a consistent and clear effect of TBC surface roughness on external heat transfer, these data will be used to determine an equivalent TBC roughness for use in the design heat load predictions on the ATS turbine airfoils. 


\section{Section 2.3 (CC) Combined Cycle Integration}

\section{Section 2.3.1 (CCSD) Combined Cycle Systems Design}

\section{Objective}

Analysis will be performed and the combined cycle system will be configured to optimize cost/performance characteristics of the total plant. Steady-state modeling will be used to calculate the detailed plant performance. Dynamic modeling of load change sequences (e.g., startup and load rejection) will be used to develop and validate control system design, and assess component design. Operability will be assessed.

\section{Progress for this Quarter}

The steady-state performance model (SSPM) for the STAG $107 \mathrm{H}$ was updated for improved maintainability and platform portability. It was also updated to include optimized design of the cooling-air cooling system (CAC) and gas fuel heating system. The $7 \mathrm{H}$ gas turbine Cycle Deck was updated and incorporated with an updated steam bottoming cycle model into the first major update of the 107H reference plant SSPM. Extension of both the STAG $109 \mathrm{H}$ and $107 \mathrm{H}$ SSPMs to include automation of design point calculations continued. Vendor evaluation for compliance of STAG $109 \mathrm{H}$ heat recovery steam generator (HRSG) functional specifications was completed. The STAG $109 \mathrm{H}$ thermal dynamic model (TDM) was successfully extended to simulate a Hot Restart and Load Change transients that were released for general design purposes. This completes the Revision 0 round of transient runs for dynamic modeling. A higher fidelity gas turbine model was incorporated into the TDM, and preliminary tests at full speed, full load conditions (FSFL) were successful.

\section{Plans for Next Quarter}

Updating of the $9 \mathrm{H}$ gas turbine Cycle Deck and steam bottoming cycle into the SSPM will continue. Work will continue on extending both the STAG 109H and 107H SSPMs to include automation of design point calculations. System design/optimization for dual fuel (gas, distillate) combined cycle configuration of STAG $109 \mathrm{H}$ will be performed. Work will continue on final definition of all machine operating limits for use in the final system design and implementation into the control system. The TDM upgrade to a higher fidelity gas turbine model will continue. Transient operability studies to optimize combined cycle system for utility duty cycles will continue.

\section{Technology Application}

Operability evaluation of the STAG $109 \mathrm{H}$ configuration will be directly applicable to the STAG 107H ATS plant. Cooling-air cooling and fuel heating system conceptual designs will be very similar for the STAG $107 \mathrm{H}$ ATS plant.

\section{Section 2.3.2 (CCUA) Unit Accessories}

\section{Objective}

Development of four new unit accessories-fuel heating, cooling-air cooling, steam cooling, and clearance control-is critical to the development of the ATS gas turbine in order that the 
gas turbine meet its performance goals and function properly. The ATS turbine employs a DLN 2.6 combustion system that requires the gas fuel to be heated in order to achieve the overall ATS efficiency goal. The cooling-air cooling system is required to maintain temperature in sections of the gas turbine within acceptable limits. The steam cooling system is required to cool the turbine hot gas path parts while meeting performance goals for the ATS turbine. The clearance control system enables the turbine to operate at a higher efficiency than would be possible without it. The exhaust diffuser will be designed so that maximum possible pressure recovery will be realized, thus increasing the performance of the ATS gas turbine. Designs of remaining accessory systems will be conventional.

Design of the heat exchanger and piping for the hot fuel will take into consideration the need to avoid coking. Deposit formation will be investigated. The effectiveness of coke barrier coatings, which have been under development for liquid-fueled systems, will be evaluated in long-term tests.

\section{Progress for this Quarter}

\section{Fuel Heating System}

A preliminary functional specification was completed that defined the design parameters of the individual components of the gas fuel heating system. This specification will be used in the supplier selection process, and the supplier will use it in developing the detailed design of the gas fuel heating system components.

\section{Cooling-Air Cooling System}

The feasibility study of the cooling-air cooling system (CAC) configuration (begun in $4 \mathrm{Q} 96$ ) continued. By the end of 1996, the estimated cost of the current high pressure (HP) configuration was found to be extremely high. Further study of the HP system in 1997 (which included less conservative design assumptions and alternate suppliers) still resulted in a very high-cost HP system. In addition, a Flowmaster model was developed that revealed that the HP system would require boost compressors (the CAC system has a very tight air pressure budget). This requirement would, in turn, drive the system cost even higher.

To address these issues, the CAC system engineering team focused on reducing system complexity and cost by eliminating components and easing system design requirements. This reduction was accomplished by the end of $1 \mathrm{Q} 97$ by making two design changes: (1) changing from an HP system to an intermediate pressure (IP) CAC system, and (2) opening the gas turbine CAC flow path to reduce pressure drop. An IP system, which operates at a much lower water pressure, would lower the cost of all CAC system components. In addition, the IP system would not require an economizer. Elimination of the economizer, paired with opening of the gas turbine CAC flow path, also obviated the need for the boost compressors. These changes not only significantly reduce the cost of the CAC system, but also increase the reliability since there will be fewer components and a lower working pressure. Although the IP system will operate at a lower combined cycle efficiency than the HP system, the fact that the HP system would require boost compressors cancels out the efficiency difference. 


\section{Steam Cooling System}

The steam cooling system $P \& I D$ was completed, and detailed component design has started. Using supplier input, the design of the components was changed/improved, working toward a design that will be more reliable and easier to install and maintain. Once the detailed designs are established with suppliers, the design specification will be completed. This is expected to take place in 1997.

\section{Clearance Control System}

In 1Q97, the Advanced Gas Turbine Design Memo Book was updated with the remaining undefined design requirements for the clearance control system (CCS) in accordance with a design review held in 4 Q96. As these remaining design requirements were being defined in 1Q97, further development of the gas turbine revealed that a higher pressure ratio CCS compressor was required. This requirement resulted in a considerable system cost increase and complexity (related to meeting the required CCS air temperature). A second design review was held to address this problem. In the review, all design parameters for the system were reconsidered as well as all gas turbine design requirements for the system. The conclusion was that the CCS operating pressure would be doubled, which would enable use of a much lower pressure ratio (and thus lower cost) compressor, and that more variability would be added to the system to provide greater operating margin as insurance for a successful first run. With these new requirements established at the end of 1Q97, the Design Memo Book will be updated with all the CCS design requirements documented to enable detailed design of the system to begin.

\section{Exhaust Diffuser System}

The detailed design of the new $\mathrm{F}$ machine diffuser was developed by GE with its suppliers. Based on this design, a preliminary outline drawing for the $\mathrm{H}$ machine exhaust diffuser was completed. At the same time, a scale model test was conducted at CRD. The purpose of the model test was to verify the flow characteristics of the diffuser and to determine whether the diffuser will meet its performance goals. Completion of the model test is expected early in 2Q97. The test results will indicate whether the current configuration is acceptable. If it is, the functional specification, outline drawing, and detailed design work will begin in $2 \mathrm{Q} 97$. If not, a new configuration must be developed and tested.

\section{Plans for Next Quarter}

\section{Fuel Heating System}

The engineering design team will select suppliers and begin to develop the detailed design of the various gas fuel heating system components with them. As the components are developed, the final functional specification will be written and released.

\section{Cooling-Air Cooling System}

With the conceptual system configuration of the cooling-air cooling (CAC) system completed in 1Q97, the P\&ID will be developed in 2Q97. At the same time, the engineering design team will begin to work with suppliers in defining the individual components of the CAC system. 


\section{Steam Cooling System}

The detailed design of the steam cooling system components will continue to be defined by the engineering design team and its suppliers. When the detailed design is complete, the design specification for the steam cooling system will be developed.

\section{Clearance Control System}

The engineering design team will select suppliers and begin to develop the detailed design of the various clearance control system components with those suppliers. As the components are developed, the final functional specification will be written and released.

\section{Exhaust Diffuser System}

The CRD model test will be completed. If results show that the new planned configuration is acceptable and the diffuser will meet its performance target, then the engineering design team will develop the functional specification and outline drawings defining the new configuration. They will also work with suppliers in developing the detailed design of the exhaust diffuser. If the results of the model test show that the new exhaust diffuser configuration will not meet its performance target, then an alternate configuration will have to be developed and tested during 2 Q97.

\section{Technology Application}

Development of the fuel heating system, the cooling-air cooling system, the steam cooling system, the clearance control system, and the exhaust diffuser system are all critical to successful operation of the ATS gas turbine. Each system is also critical to the high efficiency rating that the ATS gas turbine will achieve. Therefore development of these systems will continue in order that the ATS gas turbine meet these design goals.

\section{Section 2.3.3 (CCCL) Controls}

\section{Objective}

An integrated plant control system will be developed and designed that will be suitable for the advanced gas turbine combined cycle power plant. Specifications of control equipment requirements will be prepared. Control and protection strategies will be developed for gas turbine steam cooling and integration with the steam turbine and heat recovery steam generator (HRSG). Control system dynamic behaviors will be studied by dynamic simulations. Specifications of control algorithms will be prepared for implementation in the control system program.

\section{Progress for this Quarter}

Study of the control loop dynamics continued. The control sequences for startup and shutdown were studied, including the transfer strategies between air cooling and steam cooling. Control algorithms for startup and shutdown of the gas turbine were developed. Work is continuing on development of other control algorithms, such as steam cooling. Work also continued on development of a standard graphics philosophy for the control system. In the development of an integrated control system, the conceptual design was completed and design and manufacturing processes are underway. 


\section{Plans for Next Quarter}

Study of control loop dynamics will continue. Software algorithms will be defined for gas turbine, steam turbine, and HRSG controls. Software algorithms and sequence logic will be defined for auxiliary systems. Graphics philosophy concepts will be established. The design of the integrated control system will be completed.

\section{Technology Application}

The integrated plant control system conceptual design for the STAG $109 \mathrm{H}$ configuration will be very similar to that of the STAG $107 \mathrm{H}$ ATS plant.

\section{Section 2.3.4 (CCRA) Reliability, Availability, and Maintainability (RAM) Analysis}

\section{Objective}

An evaluation of the reliability, availability, and maintainability (RAM) of the $7 \mathrm{H}$ equipment will be performed. The basis for the work will be the EPRI High Reliability Controls and Accessories Study. The RAM analysis will include: the flange-to-flange gas turbine, heat recovery steam generator, steam turbine, controls and accessories, electrical generator, and balance of plant equipment. A failure modes and effects analysis (FMEA) will be included.

\section{Progress for this Quarter}

Activity during this reporting period has been restricted to FMEAs.

Gas Turbine Flange-to-Flange - Turbine and Compressor

FMEA development continued on all unconventional aspects of the turbine and compressor. The following systems were completed: steam gland, third-stage bucket cooling delivery, exhaust frame cooling systems Nos. 1 and 2, and steam delivery bore tube, and compressor rotor/cooling. The following systems were partially completed (10\% to $80 \%)$ : variable guide vane (VGV) assembly, second-stage nozzle, second-stage bucket, and turbine third-stage nozzle.

In addition, Greenville is planning FMEAs on the turbine base and some of the gas turbine piping. Gas Turbine Engineering now has a full-time FMEA Coordinator in-house to assist the responsible engineers with their assigned responsibilities.

\section{Plans for Next Quarter}

FMEA development will continue on the following: turbine stator system, compressor, combustor, steam delivery system, and turbine stator.

\section{Téchnology Application}

The FMEA results will be applied to the design of the $9 \mathrm{H}$ and $7 \mathrm{H}$ hardware, with special emphasis on the components involved with the steam cooling aspects of the design. 


\section{Section 2.4 (MF) Manufacturing Equipment and Tooling}

\section{Objective}

The materials, equipment, tooling, and processes required to produce the $7 \mathrm{H}$ and $9 \mathrm{H}$ turbines will be identified. Manufacturing schedules will be established to support ATS pre-commercial demonstration goals. Manufacturing schedules and cost will be defined.

\section{Progress for this Quarter}

The rotor forging tooling was modified to incorporate required changes. The IN718 turbine rotor forgings were processed for delivery to the ultrasonic inspection techniques (UT) and machining supplier. TBC process qualification continued for airfoil components. The full speed, no load (FSNL) test stand design concept was completed and work began to procure equipment to support FSNL testing.

\section{Plans for Next Quarter}

Activity will be centered around component hardware completion and delivery for the $9 \mathrm{H}$ turbine. Detailed design of the FSNL test stand will be completed, and the site approval process will begin.

\section{Technology Application}

Development of the turbine wheel forging dies and the ultrasonic inspection techniques are the first application in forgings of this size and will be used to provide high-strength, hightemperature material that is compatible with the steam cooling environment in the ATS turbine rotor. The mockups are being used to assure fit-up of all components in very restrictive areas of the turbine. An electronic simulation of these areas is being done in parallel to develop simulation technology for future applications. The TBC robot controllers will provide the thickness control for the TBC coating that is required for proper heat transfer properties in the steam-cooled turbine airfoil components.

\section{Section 2.5 (IG) Integrated Gasification and Biomass Fuel}

\section{Objective}

An assessment of the ATS will be performed as part of an efficient and environmentally compatible integrated gasification combined cycle (IGCC) power generation system. Modifications to the gas turbine to accommodate the high mass flow resulting from the low heating value fuel gas and nitrogen injection for low NOx emissions will be identified. Analyses will be run to optimize the integration of the steam cycle with one oxygen-blown entrained flow gasifier and gas cleanup system and integration of the gas turbine with the air separation unit. IGCC system performance will be analyzed for one coal composition at ISO ambient air conditions.

\section{Progress for this Quarter}

There was no activity associated with this task under the ATS Phase 3 Cooperative Agreement during the current reporting period. 


\section{Plans for Next Quarter}

There is no activity planned for this period.

\section{Section 2.6 (DE) Pre-Commercial Demonstration}

\section{Objective}

A commercial proposal will be prepared and submitted to the host utility.

\section{Progress for this Quarter}

Commercial activity remains high. Excess of generating capacity in the domestic market continues to delay project approvals; however, commercial discussions (equity shares, price, shipment requirements, insurance premiums, performance levels, construction financing, and service agreements) with potential host utilities and power marketers continue to intensify.

\section{Plans for Next Quarter}

GE will continue to support the potential host utilities' technical and commercial evaluations. The sixth Utility Advisory Board (UAB) meeting is scheduled for May 1997. In addition to updating UAB members on the status of ATS gas turbine performance, operability, maintainability, reliability, availability, plant arrangements, and installed costs, a review of the critical-to-quality (CTQ) criteria for this design will be held.

\section{Section 2.7 (PM) Program Management}

\section{Objective}

Within GEPG Engineering, an ATS Program Office will be established and a Program Manager and a Contract Administrator will be assigned. The Program Manager will direct the overall activities of the Program Office, and will have responsibility for reporting to DOE and ensuring that the program goals are achieved. The Program Office is responsible for communicating contract requirements, authorizing applied labor and expenses for material and services, scheduling, monitoring, and reporting cost and technical performance. Additional responsibilities include coordinating ATS activities with CRD and GEAE. The assigned Contract Administrator will support the Program Manager in all administrative matters. All materials and equipment acquisitions will be closely monitored by the Program Office with support from the Finance and Sourcing organizations.

Actual scope, schedule, and budget will be tracked against plan. An integrated program plan will be maintained, including a detailed Work Breakdown Structure, that accurately describes the planned work, reflecting all changes in work scope or schedule. The integrated program plan includes the implementation and coordination of all program support procedures and initiatives such as Target Costing, Key Quality, and Design for Manufacturing.

Reports will be prepared to serve both DOE and GE needs for oversight and monitoring, including quarterly reports, annual reports, and topical reports. A final report will be prepared at the completion of the cooperative agreement. Reports specified in the Cooperative Agreements Financial Assistance Reporting Requirements Checklist will be supplied. 
Technical papers will be submitted for presentation to professional society meetings. Open communications will be maintained with DOE and the Industry Advisory Board.

\section{Progress for this Quarter}

The GE ATS Program Office provided an overview briefing at Morgantown, WV, for the new FETC Director and her staff on January 31, 1997. DOE FETC indicated that Phase 4 might be canceled in favor of a revised Phase 3. The request for a restructured ATS Program was received in early March. GE Power Systems is in the process of responding with a proposal consistent with this request. 